\title{
Has the HIV epidemic peaked?
}

John Bongaarts

Population Council

Thomas Buettner

Gerhard Heilig

Francois Pelletier

Follow this and additional works at: https://knowledgecommons.popcouncil.org/departments_sbsr-pgy

Part of the Demography, Population, and Ecology Commons, Family, Life Course, and Society Commons, Gender and Sexuality Commons, Immune System Diseases Commons, International Public Health Commons, Rural Sociology Commons, and the Virus Diseases Commons How does access to this work benefit you? Let us know!

\section{Recommended Citation}

Bongaarts, John, Thomas Buettner, Gerhard Heilig, and Francois Pelletier. 2008. "Has the HIV epidemic peaked?" Poverty, Gender, and Youth Working Paper no. 9. New York: Population Council. Version of record: https://doi.org/10.1111/j.1728-4457.2008.00217.x

This Working Paper is brought to you for free and open access by the Population Council. 


\section{POVERTY, GENDER, AND YOUTH}

\section{Has the HIV Epidemic Peaked?}

John Bongaarts, Thomas Buettner, Gerhard Heilig, and François Pelletier 


\section{(1) Population Council}

One Dag Hammarskjold Plaza

New York, New York 10017 USA

www.popcouncil.org

pubinfo@popcouncil.org

For information on Poverty, Gender, and Youth working papers, see www.popcouncil.org/publications/wp/index.html

This material may not be reproduced without written permission from the authors.

ISSN: $1554-8538$

(C) 2008 The Population Council, Inc. 


\title{
Has the HIV Epidemic Peaked?
}

\author{
John Bongaarts \\ Thomas Buettner \\ Gerhard Heilig \\ François Pelletier
}

The views and opinions expressed in this paper are those of the authors and do not necessarily represent those of the United Nations. This paper has not been formally edited and cleared by the United Nations. John Bongaarts is Vice President and Distinguished Scholar, Population Council, New York. Thomas Buettner is Assistant Director, Gerhard Heilig is Chief of the Estimates and Projections Section, and François Pelletier is Chief of the Mortality Section, Population Division, United Nations. 


\begin{abstract}
This study first reviews the highly diverse regional and country patterns of HIV epidemics and discusses possible causes of the geographic variation in epidemic sizes. Past trends and projections of the epidemics are presented next and the peak years of epidemics are estimated. The potential future impact of new prevention technologies is briefly assessed. A final section summarizes the future impact of the epidemic on key demographic variables. The main finding of this analysis is that the HIV epidemic reached a major turning point over the past decade. The peak years of HIV incidence rates are past for all regions, and the peaks of prevalence rates are mostly in the past except in Eastern Europe, where it is expected to peak in 2008. But owing in part to the life-prolonging effect of antiretroviral therapy and to sustained population growth, the absolute number of infected individuals is expected to keep growing slowly in sub-Saharan Africa and remain near current levels worldwide, thus posing a continuing challenge to public health programs. No country is expected to see a decline in its population size between 2005 and 2050 that is attributable to high mortality related to AIDS.
\end{abstract}


Over the past quarter century the HIV virus has spread to all corners of the globe, resulting in one of the deadliest epidemics of modern times. In 2007 a total of 2.1 million men, women, and children died of AIDS. The death toll will remain high in the future because 33.2 million individuals are currently infected and about 2.5 million new HIV infections occur each year (UNAIDS 2007). Most of these currently and newly infected individuals are likely to die of AIDS eventually, despite the increasing availability of treatment.

In response to this unprecedented health threat a massive global effort has been mounted to reduce infections through prevention programs and to extend the lives of infected individuals with antiretroviral therapy (ART). Prevention efforts are partly responsible for a major turning point in the epidemic: after a period of rapid spread the epidemic appears to have stabilized in most countries, and the proportion of adults infected with HIV is no longer increasing (Shelton et al. 2006; UNAIDS 2007). In a number of countries the proportion infected is even declining.

The first part of this article reviews the highly diverse regional and country patterns of HIV epidemics and discusses possible causes of the geographic variation in epidemic sizes. We describe past trends in HIV epidemics and offer explanations for the recent stabilization and/or decline of the epidemic. Next, we examine projections of the future course of the epidemic, estimate the peak years of regional epidemics, and briefly assess the potential future impact of new prevention technologies. We conclude with a summary of the past and projected future impact of the HIV/AIDS epidemic on key demographic variables, including the crude death rate, the population age structure, and population growth.

\section{Current Status of The EPIDEMiC ANd Causes of Geographic VARIATION}

Worldwide approximately 0.8 percent of adults are infected with HIV. This global average conceals wide variation among regions (UNAIDS 2007). Figure 1 presents regional estimates of HIV prevalence in 2005, measured as the percent of adults aged 15-49 who are currently infected. Prevalence in all world regions except sub-Saharan Africa is a fraction of 1 percent. In contrast, prevalence in sub-Saharan Africa is 5.0 percent - an order of magnitude larger than in the rest of the world. Even larger differences in epidemics exist within sub-Saharan Africa, where prevalence levels range from a fraction of 1 percent in several countries in Western Africa to above 15 percent in some countries in Eastern and Southern Africa. The astounding concentration of the epidemic in a small region of the world is clear from the world map in Figure 2. Within-country variation in HIV prevalence can also be large, but we do not address this issue here.

Estimates of HIV prevalence and incidence are uncertain for many countries. This is especially the case in developing countries that have not conducted a nationally representative survey to measure prevalence. Our analysis therefore emphasizes regional patterns, which are somewhat more stable. Unless otherwise noted all country and regional estimates and projections in this study are taken or calculated from data provided by the United Nations (2007), updated with estimates from UNAIDS (2007). See the Appendix for details.

Large generalized epidemics are devastating, but they are also relatively rare. This finding is consistent with the fact that HIV is not a particularly infectious agent in heterosexual relationships, which are the dominant mode of transmission in most countries. On average the risk of transmission between an infected man or woman and his or her uninfected heterosexual partner 
is about 1 in 1000 (Gray et al. 2001; Wawer et al. 2005). ${ }^{1}$ This low level of infectiousness apparently is sufficient to keep the epidemic confined to a small portion of the population in most countries. The reasons for the explosive epidemics in parts of Eastern and Southern Africa remain controversial, but the following factors are considered critical to the rapid spread of the virus (Caldwell 2000; Cameron et al. 1989; Halpern and Epstein 2007; Quinn et al. 2000; Shapiro 2002).

\section{Multiple and concurrent sexual partners}

Because the HIV virus in sub-Saharan Africa is spread primarily through sexual contact between men and women, it is reasonable to assume that variation in sexual behavior is a source of variation in epidemics. But frequency of sex alone is not a useful indicator of risk because a heterosexual epidemic cannot occur in a population in which all sex takes place in monogamous unions. The key factor is not frequency of intercourse but frequency of partner change and the number of concurrent partners. ${ }^{2}$ Epidemiological models have demonstrated the critical role of a high rate of new partner acquisition and sexual mixing patterns in the spread of HIV (Anderson 1996, 1999). For uninfected individuals frequent partner change raises the risk of encountering an infected partner, and for infected individuals any new partner implies a new chance to spread the infection. Concurrent partnerships appear to be particularly conducive to the spread of HIV through networks of individuals, and these partnerships appear to be more common in subSaharan Africa than in other world regions (Epstein 2007; Halperin and Epstein 2004, 2007; Morris and Kretchmar 1997; Orubuloye et al. 1994; Swidler and Watkins 2007). This topic is difficult to study because nationally representative estimates of sexual behavior have limited data on partner concurrency, and the validity and reliability of self-reported behavior on this topic are unclear (Cleland et al. 2004).

Indirect evidence supporting the key role of multiple partners is provided by a recent study by Bongaarts (2007) of the ecological correlation between HIV prevalence and the age at first sex and first marriage among females. This analysis of aggregate data from 33 sub-Saharan countries found no correlation between HIV prevalence and the average age at first sex, but epidemic size was strongly and significantly correlated with the average age at marriage and the interval between age at first sex and first marriage. ${ }^{3}$ Countries with very large HIV epidemics (Botswana, South Africa, and Namibia) have ages at marriage in the mid-20s, which is much higher than elsewhere in the continent. Late age at marriage results in a long period of premarital sex because age at first sex in these late-marrying populations is not higher than elsewhere. This long interval of premarital sex apparently puts women at elevated risk as a result of frequent partner change, multiple concurrent partners, and high partner infectiousness, thus facilitating the spread of HIV.

\section{Absence of male circumcision}

A potential role for a protective effect of male circumcision was first proposed in the late 1980s when ecological and prospective clinical studies in sub-Saharan African populations found a highly significant inverse correlation between levels of male circumcision and HIV prevalence (Bongaarts et al. 1989; Cameron et al. 1989; Moses et al. 1990). Recent reviews of the accumu- 
lated evidence confirm the higher risk of HIV infection among uncircumcised males (Bailey et al. 2001; Epstein 2007; Halperin and Bailey et al. 1999; Weiss et al. 2000). These findings have been controversial and proposals to introduce male circumcision as a preventive measure have not been actively considered until very recently. Any doubts about the effects of male circumcision were removed with the conclusion of three recent randomized controlled trials in Kenya, South Africa, and Uganda (Auvert et al. 2005; Bailey et al. 2007; Gray et al. 2007). The reduction in the risk of infection in these three trials was 50-60 percent, thus demonstrating conclusively that male circumcision is protective. It is unfortunate that circumcision programs were not implemented earlier.

The main biological explanation for the observed protective effect of male circumcision on HIV acquisition involves the dendritic cells on the inner side of the foreskin. These cells are particularly susceptible to HIV infection, and circumcision removes this vulnerable point of entry for HIV (Vachot et al. 2006). In addition to this direct effect, uncircumcised men are at higher risk of infection with certain other sexually transmitted infections (STIs), such as chancroid and syphilis, that have been associated with increased risk of transmission of HIV (Weiss et al. 2000). Male circumcision is thus likely to have both a direct effect on transmission and an indirect effect by reducing the incidence of some ulcerative STIs. The protective effect of male circumcision is partial and circumcised men are still at risk although at a lower level; they should therefore continue to use condoms.

\section{Other sexually transmitted infections}

Certain STIs (e.g., chancroid, genital herpes, and syphilis) raise the risk of HIV transmission directly by causing genital ulcers (Auvert et al. 2001; Bailey et al. 2001; Brown et al. 2007; Cameron et al. 1989; Fleming and Wasserheit 1999). In addition, STIs may have an indirect effect on HIV transmission by raising virus levels in the blood and in other bodily secretions (Quinn et al. 2000). STIs are more common in sub-Saharan Africa than in other world regions (Chin 2007; WHO 1999).

\section{Absence of condom use}

If used consistently, condoms provide a high degree of protection against HIV infection and against infection with other STIs. Condom use is rare: about 1 percent among married couples in sub-Saharan Africa (United Nations 2006); and even among men having commercial sex, on average only half report using a condom at the last sexual intercourse (DHS 2007). In generalized heterosexual epidemics, compliance is below the level needed to have a significant impact on the epidemic (Hearst and Chen 2004).

It is beyond the scope of this study to quantify the role of each of these factors in determining the size of HIV heterosexual epidemics. Such an analysis is difficult given the lack of reliable measures of these determinants. It should be noted, however, that apparently all four of these factors are present in the largest epidemics. The presence of one or two alone is not sufficient to cause substantial epidemics. For example, male circumcision is rare in much of Western Europe, marriage is late, and most men and women have multiple partners during their sexually 
active years. Yet HIV prevalence is very low among heterosexuals in Western Europe. The likely explanation is the protective effect of condom use, the near absence of other STIs, and the lower prevalence of concurrent partnerships. In contrast, Southern Africa's epidemics are very large because multiple and concurrent partnerships are relatively common, male circumcision and condom use are relatively rare, and other STIs are highly prevalent.

\section{THE EVOLUTION OF THE EPIDEMIC}

Trends in HIV epidemics vary between countries and regions, but a general pattern consisting of a slow start in the early 1980s or 1990s, followed by a period of rapid expansion and ending with an endemic plateau, is apparent. HIV prevalence levels (adults 15-49) by region from 1980 to 2005 are plotted in Figure 3. (The vertical line in this and other figures separates estimates up to 2005 and projections from 2005 onward.) Similar patterns are observed for individual countries. For example, Figure 4 presents prevalence trends for sub-Saharan countries. Epidemics vary in their starting date and size, but the general shape of the prevalence pattern is similar. Nearly all these epidemics reached their peak in the 1990 s or the early 2000s.

The appearance of recent plateaus is one of the epidemic's most interesting and important features. A stable prevalence level implies that the virus is present in a small proportion of the population but is nevertheless not spreading further. An explanation of this phenomenon is that every population is a heterogeneous mixture of subgroups with widely varying infection risks. At the high end of the risk spectrum are sex workers and their clients, needle-sharing intravenous drug users (IDUs), and homosexual men, and at the low end are men and women living in monogamous unions or without sexual partners. The epidemic is often self-sustaining in the former groups but not in the latter. At the onset of an epidemic the virus quickly invades the groups at highest risk, but it then encounters resistance when the pools of high-risk individuals become infected or die out. The overall size of the epidemic depends on the sizes of the different risk groups. In the United States and Europe, for example, parts of the homosexual and IDU groups are at relatively high risk, but infection risks are very low for the vast majority of heterosexuals. As a result, HIV prevalence among heterosexuals in these regions is a fraction of 1 percent. In contrast, Southern African populations have substantial high-risk groups of sex workers and their partners, and the virus spreads more readily in the general population through diffuse networks of multiple and concurrent partners. An epidemic reaches a plateau when the virus has achieved maximum penetration of the vulnerable subgroups. This point seems to have been reached in most countries in the world by the early 2000s.

HIV prevalence is actually declining in a number of countries. Such declines could be attributable to an increase in the number of AIDS-related deaths, but behavior change provides an alternative partial explanation. For example, in Uganda prevalence was cut almost in half from 11.8 percent to 6.7 percent between 1991 and 2005 (see Figure 4). The causes of this decline are controversial, but the evidence for behavior change is strong. Both men and women report a decline in sex with non-regular partners and a rise in condom use (Bessinger et al. 2003; Kilian et al. 1999; Singh et al. 2003; Stoneburner and Low-Beer 2004). Similar trends are observed in a prospective study in eastern Zimbabwe that documented a decline in HIV prevalence associated with changes in high-risk sexual behavior (Gregson et al. 2006). Substantial declines in high-risk 
behavior and infection rates have also occurred among homosexual men in North America and Europe and among heterosexuals in Thailand during the 1980s and 1990s (UNAIDS 2006). These examples demonstrate that substantial changes in behavior can take place when individuals become aware of the health risks of their behavior. Evidence of such behavior changes is not clear-cut for many other countries in sub-Saharan Africa (Bessinger et al. 2003; United Nations 2005). There is little evidence of behavior change in some of the countries with the largest epidemics in Eastern and Southern Africa despite widespread knowledge of the AIDS epidemic and its causes, but even here the epidemics are no longer growing.

Figures 3 and 4 also include UN projections of HIV prevalence rates from 2005 to 2025. These projections are based on a model developed by the UNAIDS Reference Group on Estimates, Modelling and Projections (UNAIDS Reference Group 2002) that was adopted and customized by the Population Division for its own purposes. This model is fitted to past estimates of HIV prevalence provided by UNAIDS for each of the affected countries and then extrapolated. In the large majority of countries the projections assume that prevalence continues its slow decline observed before 2005. In the few countries where prevalence is still rising, the model predicts a peak and a subsequent decline based on the epidemic pattern observed before 2005. Further details on the projection methodology are provided in the Appendix.

\section{Has The HIV EpIDEMic PeAKed?}

The preceding analysis relied on HIV prevalence rates to assess trends in the sizes of epidemics. HIV prevalence is the most widely available indicator of epidemic size and it is readily interpreted. But there are three concerns about this indicator's ability to track the epidemic's ups and downs accurately.

The first is that prevalence is a lagging indicator of HIV infections. The numerator of the HIV prevalence rate consists of all currently infected adults aged 15-49, regardless of when they were infected. Because individuals survive about a decade after infection, the prevalence estimate in a given year is determined by the number of infections that occurred in the past decade or longer.

The second concern is that HIV prevalence is affected by the treatment of AIDS patients. Contemporary antiretroviral therapy can be highly effective in keeping AIDS patient alive for years beyond the time associated with the natural course of the disease. This keeps the pool of infected individuals larger (and the HIV prevalence rate higher) than would be the case without treatment. 4

The third concern is that HIV prevalence is affected by a rise in the AIDS death rate. As the epidemic matures, the death rate tends to rise as infected individuals age, and every AIDS death reduces the number of infected people.

For these reasons many epidemiologists prefer another indicator to track epidemic trends: the HIV incidence rate, defined as the annual rate of new infections among adults aged 15-49. The total infected population at a point in time is the net result of past additions to the infected population through new infections and subtraction through deaths. The rate of new additions to the pool of infected individuals is measured by the incidence rate. 
Figure 5 presents UN estimates of incidence rates by region. The pattern over time is broadly the same in all regions: a rapid rise to a peak followed by a slower decline. As expected, the incidence peak in sub-Saharan Africa ( 0.8 percent per year) is far higher than in other continents, where the peaks are all less than 0.1 percent per year. The timing of the incidence peaks also varies significantly. The first peak occurred in the 1980s in North America (1983) and Latin America (1987), followed by sub-Saharan Africa (1991) and Asia (1995). Europe has two peaks, the first in 1983 in Western Europe and the second in 2001 in Eastern Europe. The global peak in incidence occurred in 1995 at a rate of 0.1 percent per year. The ongoing declines in incidence are caused by the same factors noted above for prevalence trends: saturation of infection among high-risk groups and changes in behavior. But there is an additional third factor: a decline in the average infectiousness of infected individuals. This decline is a result of a rising average duration since the time of infection as the epidemic matures, combined with a reduction in individual infectiousness with time since infection.

A comparison of Figures 4 and 5 shows that the peaks in incidence precede the peaks in prevalence by nearly a decade. This implies that prevalence continues to rise for a number of years after the incidence rate has begun to decline. This is possible because the prevalence rate is calculated from the number of individuals who are currently infected regardless of when in the past the infection occurred. For example, in a hypothetical case in which all infected individuals survive exactly ten years, the prevalence rate at any given point in time equals the sum of all infections that occurred in the past ten years, regardless of whether the annual number of new infections was rising or falling. The number of infected individuals reaches a maximum when the declining number of new infections equals the rising number of AIDS deaths. This point is typically reached a number of years after the peak in HIV incidence.

Figure 6 summarizes the peak years for incidence and prevalence rates for the world and for major regions. The left end of each bar represents the year of the incidence peak and the right end represents the peak year for prevalence. For example, world incidence peaked in 1995 and world prevalence in 2003, a difference of eight years. As noted, the first incidence peak occurred in North America and the last one in Eastern Europe. The prevalence peaks occur nearly a decade later except in Asia, where the delay is shorter. The main finding from this analysis is that the peak years of HIV incidence have passed for all regions, and the peaks of prevalence are mostly in the past except in Eastern Europe, where it is expected to occur in 2008.

The preceding discussion of epidemic trends relied on incidence and prevalence rates to quantify epidemic sizes. An alternative measure of epidemic size is simply the absolute number of newly or currently infected individuals. Analysis of absolute numbers has been avoided here because they are affected by population size, thus potentially giving misleading results. For example, in 2006 the number of infected adults in China is estimated to have been more than twice the number of infected individuals in Botswana. But the HIV prevalence rate in Botswana (24 percent) is more than 200 times the rate in China ( 0.1 percent). It is clear that the societal impact of the epidemic is better measured with the prevalence rate than with the absolute numbers infected. Nevertheless, absolute numbers are sometimes useful, for instance for the allocation of international resources to combat the epidemic. Figure 7 presents the absolute annual number of new infections by region. As expected, sub-Saharan Africa has the largest number of new infections per year. Asia is second because a low incidence is applied to a much larger population. 
The number of new infections worldwide peaked in the mid-1990s at just over 3 million per year, then declines to 2010 , followed by a plateau until about 2030 as population growth offsets the continuing decline in the incidence rate. Figure 8 presents absolute numbers of infected adults aged 15-49 by region. Africa and Asia are again the highest and second highest regions. The world total reached 29 million in 2006 and is expected to remain near this level for several decades. The peak in the number of infected individuals in sub-Saharan Africa is not expected until around 2030. As noted, population growth and the extension of the lives of AIDS patients due to ART are largely responsible for this trend.

\section{New Prevention Technologies and Their Potential ImPact}

The future spread of HIV can be reduced with more vigorous prevention efforts. Prevention options can be divided into those that are widely available today and encouraged by most ongoing intervention programs and those that depend on the development and introduction of new technologies. The former include abstinence, reduction in number of partners, and condom use.

Prevention programs, by broadcasting motivational messages, have encouraged abstinence, sexual fidelity, and condom use in many settings, even though the question as to which of these prevention interventions should be given highest priority (in particular, the role of abstinence vs. condom use) is controversial (Merson 2006). Secondary transmission of HIV from an infected mother to her newborn can be prevented by the use of antiretroviral drugs, by encouraging safer infant feeding practices, and by improving access to contraception to prevent unwanted pregnancies. Declining prevalence rates in several countries are consistent with the view that these prevention efforts have had an impact. Despite these encouraging trends in a few populations, however, high-risk behavior remains pervasive and HIV continues to spread in much of the world. In addition, many women who wish to protect themselves lack the cooperation of their partners. To make prevention efforts more effective, a massive global effort is underway to develop, test, and introduce prevention technologies, such as male circumcision, microbicides, and vaccines.

\section{Male circumcision}

As noted, recently concluded randomized controlled trials confirmed the substantial protection male circumcision provides against HIV infection. Shortly after the publication of these results a joint WHO/UNAIDS Technical Consultation recommended that male circumcision be implemented in areas with a high prevalence of HIV infection (WHO/UNAIDS 2007). Because introduction of male circumcision programs is a complex process, further research is needed on a host of critical issues including acceptability among uncircumcised males, the safety of the surgical procedure, the ability of overburdened health care systems to handle a large volume of procedures, the training of medical personnel, the need to use condoms because circumcision is only partially effective in preventing infection, the target age group (infants, adolescents, or all adult males), and the need to prevent behavioral disinhibition (an increase in high-risk behavior following male circumcision) (Sawires et al. 2007; WHO/UNAIDS 2007). 


\section{Microbicides}

A microbicide is a vaginal product (e.g., gel or cream) that blocks the transmission of HIV during sexual intercourse. Microbicides have two highly desirable characteristics: they are under the control of women and they do not require the consent or knowledge of male partners. First-generation microbicides typically form physical barriers against the virus or change the chemistry of a woman's vagina. Ongoing trials will conclude over the next few years and any products found to be effective are expected to be approved, manufactured, and distributed relatively quickly. Second-generation microbicides promise to be more effective because they fight viral transmission through multiple mechanisms (e.g., by combining a physical barrier with an antiretroviral agent), and some of them are designed to increase adherence by making them less coital dependent and longer acting. Several such compounds are now under development (Nuttall et al. 2007).

\section{Vaccines}

A vaccine does not require daily action and is therefore the preferred prevention technology. Unfortunately, no effective vaccine candidates are available and all new experimental vaccines face big obstacles: HIV mutates rapidly to escape immune responses, and a single vaccine is unlikely to protect against the many existing HIV variants. As a result, an effective and easily manufactured vaccine is probably at least a decade away (Johnson and Fauci 2007).

Like male circumcision, microbicides and vaccines will probably be only partially effective, that is, the user's risk of infection is reduced but not eliminated. Such technologies are nevertheless crucial because each averted infection benefits the individual user directly and also reduces the risk of future infections in the general population. With consistent use, even moderately effective products can potentially avert millions of deaths. The future impact of these new technologies on the epidemic depends on how soon they become available, on how acceptable they are to users, on how effective they are if used as recommended, and on how diligent users are in following instructions. Variations in each of these factors will lead to widely different outcomes when these technologies are introduced in different populations.

To provide an upper and lower boundary on the potential impact of new technology, we compare two projections. The upper boundary for impact is provided by a projection in which all infections stop after the year 2010. This very unlikely scenario could be brought about by discovery of a new 100 percent effective vaccine and its immediate and universal application. The lower boundary for impact is given by the medium variant UN population projection, which assumes no additional prevention technology.

Figure 9 compares the future trends in HIV prevalence rates in these two projections for sub-Saharan Africa. The upper and lower bound scenarios diverge after 2010. Although no new infections occur in the upper bound scenario, there is a substantial number of infected persons in 2010 and some of these survive more than a decade. As a result, prevalence declines gradually, reaching half the 2010 level by 2016 .

The potential effect of new technologies is substantial, but the real-world impact will likely be much less than the upper boundary of impact presented here. This is demonstrated by a 
simulation study of the potential impact of male circumcision by Williams et al. (2006). Assuming an effectiveness level demonstrated in the recent trials and full circumcision coverage by 2015, this study estimates for South Africa a reduction of just 19 percent in the number of infected individuals and of 13 percent in AIDS deaths below the no-intervention scenario for the decade 2015-25. This is obviously an important step in the right direction, but falls well short of stopping the epidemic.

\section{THE DEMOGRAPHIC IMPACT OF THE HIV EPIDEMIC}

The following analysis of the demographic impact of the AIDS epidemic compares two scenarios-"AIDS" and "No-AIDS"- prepared by the United Nations Population Division as part of its 2006 Revision of the World Population Prospects (United Nations 2007). The AIDS scenario is simply the medium variant population projection, which includes the effect of the epidemic, while the No-AIDS scenario is a projection in which the mortality rates of uninfected individuals are applied to the entire population. ${ }^{5}$ It should be noted that the demographic impact incorporated in the AIDS scenario does not reflect the updates of HIV prevalence estimates made in 2007 in selected countries. The epidemic's demographic impact may therefore be slightly overestimated.

The epidemic directly affects standard demographic indicators of population mortality such as the crude death rate and life expectancy. Effects on fertility and migration also exist, but they are smaller and more complex (United Nations 2002). Changes in vital rates in turn affect population growth and the age structure. To simplify the presentation of these demographic effects, we limit the following discussion to three key indicators.

\section{Crude death rate}

Figures $10 \mathrm{~A}$ and $10 \mathrm{~B}$ plot the estimated past and projected future crude death rates with and without AIDS by world region for 1980 to 2050. As expected, the difference between these two scenarios is largest in sub-Saharan Africa. In this region, the death rate declines steadily over time in the No-AIDS scenario, while it pauses between 1985 and 2005 in the AIDS scenario before resuming a decline. The crude death rate in the AIDS scenario exceeds the rate in the NoAIDS scenario by 22 percent in $2000-05$, and this difference is projected to decline slightly by the end of the projection period. In the other regions the impact of the epidemic is an order of magnitude smaller (see Figure 10B). The largest future differences between the regional AIDS and No-AIDS scenarios range from 2 to 3 percent.

\section{Population age structure}

The rise in death rates due to AIDS varies widely by age, with the largest effects among adults aged 20-49 and among young children who are infected by their mothers around the time of birth. As a result, the epidemic has an effect on the distribution of the population by age. This effect is very small in all regions except sub-Saharan Africa. Figure 11 compares the age distribution of sub-Saharan Africa in 2015 for the two scenarios. The largest effects occur in the age groups above age 30 and below age 15, reflecting the impact of AIDS deaths that occurred before 2015. The decline in the number of children in the "AIDS" scenario is also caused by a pro- 
jected reduction in the number of women of reproductive age due to AIDS mortality. In the most heavily affected countries the changes in the age structure are more pronounced. This is evident in Figure 12, which plots the AIDS and No-AIDS age distributions for South Africa in 2015. These results are broadly consistent with the in-depth analysis of the impact of the epidemic on the population age structure by Dorrington et al. (2006).

\section{Population growth}

Excess deaths due to the HIV epidemic can have a substantial impact on population growth. Figure 13 compares regional population growth between 2005 and 2050 with and without the AIDS epidemic. In all regions the epidemic leads to lower population size in 2050, but outside sub-Saharan Africa the effect is a fraction of 1 percent and hence not visible in the graphs. The largest impact is forecast for sub-Saharan Africa, where population in 2050 is projected to reach 1.95 billion without the epidemic and 1.76 billion with AIDS (see Figure 14). The difference between these projections is due to the direct effects of AIDS deaths and the absence of descendants from individuals who have died from AIDS. A key implication of this finding is that despite the huge mortality associated with the AIDS epidemic, the population of subSaharan Africa is expected to grow by 1 billion between 2005 and 2050.

The impact on future population growth is of course larger in Southern Africa. For example, as a result of the AIDS epidemic, population size in 2050 is projected to be reduced below the No-AIDS scenario by 29 percent in South Africa and by 25 percent in Botswana. But in both countries population growth remains positive over the next several decades. The explanation for this finding is that the crude birth rate in these countries is considerably higher than the crude death rate. As a result, even a doubling of the death rate leaves the birth rate higher than the death rate, and the population continues to grow, though at a slower pace. For instance, in Botswana the birth and death rates without AIDS in 2005-10 would have been 2.5 percent and 0.6 percent per year respectively, leading to a rate of natural increase of 1.9 percent per year. The epidemic more than doubled the death rate to 1.4 percent, which — with a similar birth rategives a rate of natural increase of 1.1 percent. This large epidemic reduced the population growth rate from 2.1 to 1.2 percent per year. No country is expected to see a decline in its population size between 2005 and 2050 that is attributable to higher AIDS-related mortality. However, if outmigration reaches higher levels than projected, some countries with high AIDS prevalence

levels may experience a population decline in the coming decades, even though the rate of natural increase will most likely remain positive.

\section{CONCLUSION}

Over the past quarter century the HIV virus has spread very unevenly around the world, with very large epidemics in parts of Eastern and Southern Africa and relatively small epidemics outside Africa. The explanation for this variation lies in several epidemiological factors. The largest epidemics occur in populations where multiple and concurrent partners are relatively common, where condom use and male circumcision are rare, and where ulcerating STIs are highly prevalent. In the absence of most of these factors the HIV virus has difficulty establishing and sustaining itself, and the HIV prevalence rate is typically less than 1 percent. 
The answer to the question "Has the epidemic peaked?" depends on which indicator is used to assess epidemic trends. Although statistics on the evolution of the epidemic may contain measurement errors and the model's underlying assumptions are subject to revision, it appears that the incidence rate has peaked in all world regions and is now declining. The same is true for the prevalence rate, although the peak occurred later. Ongoing declines in incidence and prevalence rates are probably attributable to behavior change and to the natural burn-out of epidemics, which leads to the saturation of high-risk groups.

A somewhat different picture emerges when epidemic size is measured in terms of absolute numbers of infections and infected individuals. A peak in the annual number of new infections occurred in the past decade in all regions; these peaks are expected to be followed by steady declines in all regions except sub-Saharan Africa. In this region a rebound is expected as a slowly declining incidence rate is offset by a rapidly rising population size. The total annual number of new infections worldwide is projected to remain close to current levels for the next quarter century.

The HIV epidemic reached a major turning point over the past decade. Incidence and prevalence rates have peaked in all world regions between the early 1990s and 2008. But in part due to the life-prolonging effect of antiretroviral therapy and to sustained population growth, the number of infected individuals is expected to keep growing slowly in sub-Saharan Africa and to remain near current levels worldwide, thus posing a continuing challenge to public health programs. These findings indicate a continuing need to develop new prevention technologies and for prevention and treatment programs especially in the countries with substantial epidemics. They may also lead to discussion and possible revision of priorities assigned to the HIV/AIDS epidemic relative to other public health challenges in countries where the epidemic is declining.

\section{NoTES}

1 Infectiousness varies according to duration of infection, with the most infectious periods immediately following infection and after the onset of AIDS (Halperin and Epstein 2007; Shiboshki and Padian 1998; Wawer et al. 2005).

2 There is no precise standard definition of the term "concurrency," but it generally refers to an individual having a sexual relationship with more than one partner within a brief interval of time, for example a few weeks. This behavior facilitates the rapid spread of the epidemic because an infected individual is highly infectious for several weeks immediately following the time of infection (see endnote 1).

3 A regression analysis of data from 33 sub-Saharan countries found that male circumcision and duration of premarital sex together explain 64 percent of the variance in HIV prevalence (Bongaarts 2007).

4 ART has additional poorly measured effects on the spread of the incidence of HIV, including a reduction in viral load in infected individuals (making them less infectious to others), a possible increase in high-risk behavior, and the emergence of drug resistance with poor adherence to treatment. 
5 The mortality of persons who are not infected is not the same as the mortality that would have been experienced had the epidemic never occurred. This distinction is of little importance during the early years of the epidemic or in countries with small epidemics, but is more important when a sizable part of the population is infected and ultimately dies of AIDS. The difference is the result of the assumption that the epidemic is likely to affect the capacity of countries to provide health care services to its population, including uninfected people. Therefore, the assumed trends in No-AIDS mortality are somewhat less optimistic than if the epidemic had never occurred. Nonetheless, the difference between the AIDS and No-AIDS scenarios provides a useful indicator of the epidemic's impact.

\section{REFERENCES}

Anderson, R. M. 1996. "The spread of HIV and sexual mixing patterns," in J. Mann and D. Tarantola (eds.), AIDS in the World II. New York: Oxford University Press, pp. 71-86.

. 1999. "Transmission dynamics of sexually transmitted infections," in K. K. Holmes, P. F. Sparling, P.-A. Mardh et al. (eds.), Sexually Transmitted Diseases, 3rd ed. New York: McGraw-Hill, pp. 25-37.

Auvert, B., A. Buvé et al. 2001. "Ecological and individual level analysis of risk factors for HIV infection in four urban populations in sub-Saharan Africa with different levels of HIV infection," AIDS 15 (Suppl 4): S127-S131.

Auvert, B., D. Taljaard, E. Lagarde et al. 2005. "Randomized, controlled intervention trial of male circumcision for reduction of HIV infection risk: The ANRS 1265 trial," PloS Medicine 2(11): e298. DOI: 10.1371/journal.pmed.0020298.

Bailey, R. C., S. Moses, C. B. Parker et al. 2007. "Male circumcision in young men in Kisumu, Kenya: A randomized controlled trial," Lancet 369: 343-356.

Bailey, R. C., F. A. Plummer, and S. Moses. 2001. "Male circumcision and HIV prevention: Current knowledge and future research directions," Lancet Infectious Diseases 1: 223231.

Bessinger, Ruth, Priscilla Akwara, and Daniel Halperin. 2003. "Sexual behavior, HIV, and fertility trends: A comparative analysis of six countries," Phase 1 of the ABC Study. USAID and MEASURE Evaluation, a project managed by the University of North Carolina at Chapel Hill in collaboration with ORC Macro, Tulane University, and John Snow Inc.

Bongaarts, John. 2007. "Late marriage and the HIV epidemic in sub-Saharan Africa," Population Studies 61(1): 73-83. 
Bongaarts, John, Prescilla Reining, Peter Way, and Francis Conant. 1989. "The relationship between male circumcision and HIV infection in African populations," AIDS 3(6): 373377.

Boerma, J. T., K. A. Stanecki, M. L. Newell et al. 2006. "Monitoring the scale-up of antiretroviral therapy programmes: Methods to estimate coverage," Bulletin of the World Health Organization 84(2): 145-150 «http://www.who.int/bulletin/volumes/84/2/145.pdf».

Brown, Joelle M., Anna Wald, Alan Hubbard et al. 2007. "Incident and prevalent herpes simplex virus type 2 infection increases risk of HIV acquisition among women in Uganda and Zimbabwe," AIDS 21(12): 1515-1524.

Caldwell, John C. 2000. "Rethinking the African AIDS epidemic," Population and Development Review 26(1): 117-135.

Cameron, D. W. et al. 1989. "Female to male transmission of human immunodeficiency virus type 1: Risk factors for seroconversion in men," Lancet 2: 403-407.

Chin, James. 2007. The AIDS Pandemic: The Collision of Epidemiology with Political Correctness. Oxford: Radcliffe Publishing.

Cleland, J., J. T. Boerma, M. Caraël, and S. S. Weir. 2004. "Monitoring sexual behavior in general populations: A synthesis of lessons from the past decade," Sexually Transmitted Infections 80 (Suppl: Measurement of sexual behavior) II: ii1-ii7.

DHS. 2007. Tabulation created with STATCOMPILER, using data from Cameroon, Ethiopia, Ghana, Kenya, Malawi, Mozambique, Nigeria, Tanzania, Zambia, Zimbabwe. «http:// www.measuredhs.com/hivdata/data/table_builder.cfm?survey_type_id=\&survey_pop_ba sed=\&userid=48147\&usertabid=54161».

Dorrington, R. E., L. F. Johnson, D. Bradshaw, and T. Daniel. 2006. The Demographic Impact of HIV/AIDS in South Africa: National and Provincial Indicators for 2006. Cape Town: Centre for Actuarial Research, South African Medical Research Council and Actuarial Society of South Africa «http://www.commerce.uct.ac.za/Research_Units/ CARE/RE SEARCH/PAPERS/ASSA2003Indicators.pdf».

Epstein, Helen. 2007. The Invisible Cure: Africa, the West, and the Fight Against AIDS. New York: Farrar, Straus and Giroux.

Fleming, D. T. and J. N. Wasserheit. 1999. "From epidemiological synergy to public health policy and practice: The contribution to public health policy and practice: The contribution of other sexually transmitted diseases to sexual transmission of HIV infection," Sexually Transmitted Infections 75: 3-17. 
Gray, R. H., G. Kigozi, D. Serwadda et al. 2007. "Male circumcision for HIV prevention in men in Rakai, Uganda: A randomised trial,” Lancet 369: 657-666.

Gray, R., M. J. Wawer, R. Brookmeyer et al. 2001. "Probability of HIV-1 transmission per coital act in monogamous, heterosexual, HIV-1 discordant couples in Rakai, Uganda," Lancet 357(9263): 1149-1153.

Gregson, Simon, Geoffrey Garnett, Constance A. Nyamukapa et al. 2006. "HIV decline associated with behavior change in Eastern Zimbabwe," Science 311: 664-666.

Halperin, D. and R. C. Bailey. 1999. "Male circumcision and HIV infection: Ten years and counting," Lancet 354(9192): 1813-1815.

Halperin, D. and H. Epstein. 2004. "Concurrent sexual partnerships help to explain Africa's high HIV prevalence: Implications for intervention,” Lancet 364: 4-6.

- 2007. "Why is HIV prevalence so severe in southern Africa?," The Southern African Journal of HIV Medicine (March): 19-24.

Hearst, Norman and Sanny Chen. 2004. "Condom promotion for AIDS prevention in the developing world: Is it working?," Studies in Family Planning 35 (1): 39-47.

Johnson, M. I. and A. S. Fauci. 2007. “An HIV vaccine-evolving concepts," New England Journal of Medicine 356: 2073-2081.

Kilian, Albert H. D., Simon Gregson, Bannet Ndyanabangi et al. 1999. "Reductions in risk behaviour provide the most consistent explanation for declining HIV-1 prevalence in Uganda," AIDS 13: 391-398.

Merson, Michael. 2006. "Uganda's HIV/AIDS epidemic: Guest editorial," AIDS Behavior 10(4): $333-334$.

Morris, M. and M. Kretzchmar. 1997. "Concurrent partnerships and the spread of HIV," AIDS 11: 681-683.

Moses, S., N. J. D. Bradley, J. O. Ndinya-Achla et al. 1990. "Geographical patterns of male circumcision practices in Africa: Association with HIV seroprevalence," International Journal of Epidemiology 19: 693-697.

Nuttall, Jeremy, Joseph Romano, Karen Douville et al. 2007. "The future of HIV prevention: Prospects for an effective anti-HIV microbicide," Infectious Disease Clinics of North America 21: 219-239.

Orubuloye, I. O., John C. Caldwell, Pat Caldwell, and Gigi Santow. 1994. "Sexual networking and AIDS in sub-Saharan Africa," in I. O. Orubuloye, John C. Caldwell, and Gigi Santow 
(eds.), Sexual Networking and AIDS in Sub-Saharan Africa: Behavioural Research and the Social Context. Health Transition Series No. 4. Canberra: Australian National University.

Quinn, T. C., M. Wawer, N. Sewankambo et al. 2000. "Viral load and heterosexual transmission of human immunodeficiency virus type 1," New England Journal of Medicine 342: 921929.

Sawires, S. R. et al. 2007. "Male circumcision and HIV/AIDS: Challenges and opportunities," Lancet 369: 708-713.

Shapiro, R. 2002. "Drawing lines in the sand: The boundaries of the HIV pandemic in perspective," Social Science and Medicine 55: 107-110.

Shelton, James D., Daniel T. Halperin, and David Wilson. 2006. "Has global HIV incidence peaked?," Lancet 367(9517): 1120-1121.

Shiboski, Stephen C. and Nancy S. Padian. 1998. "Epidemiological evidence for time variation in HIV infectivity," Journal of Acquired Immune Deficiency Syndromes and Human Retrovirology 19: 527-535.

Singh, Susheela, Jacqueline E. Darroch, and Akinrinola Bankole. 2003. "A, B and C in Uganda: The roles of abstinence, monogamy and condom use in HIV decline," Occasional Report No. 9. New York: The Alan Guttmacher Institute.

Stoneburner, Rand L. and Daniel Low-Beer. 2004. "Population-level HIV declines and behavioral risk avoidance in Uganda," Science 304: 714-718 (30 April). «www.science mag.org».

Stover, J., N. Walker, N. C. Grassly, and M. Marston. 2006. "Projecting the demographic impact of AIDS and the number of people in need of treatment: Updates to the Spectrum projection package," Sexually Transmitted Infections 82 (Supplement 3): iii45-iii50 «http://sti.bmj.com/cgi/content/abstract/82/suppl_3/iii45».

Swidler, Ann and Susan Cotts Watkins. 2007. "Ties of dependence: AIDS and transactional sex in rural Malawi," Studies in Family Planning 38(3): 147-162.

UNAIDS Reference Group on Estimates, Modelling and Projections. 2002. "Improved methods and assumptions for estimation of the HIV/AIDS epidemic and its impact: Recommendations of the UNAIDS Reference Group on Estimates, Modelling and Projections," AIDS 16: W1-W14 «http://www.epidem.org».

UNAIDS. 2006. Report on the Global AIDS Epidemic. Joint United Nations Programme on HIV/AIDS. Geneva: UNAIDS. 
- 2007. AIDS Epidemic Update: December 2007. Joint United Nations Programme on HIV/AIDS (UNAIDS) and World Health Organization (WHO). Geneva: UNAIDS.

UNAIDS, UNICEF, WHO. 2007. Children and AIDS-A Stocktaking Report. Actions and Progress during the First Year of Unite for Children, Unite against AIDS (with Statistical Annexes). «www.unicef.org/uniteforchildren».

United Nations. 2002. HIV/AIDS and Fertility in sub-Saharan Africa: A Review of the Research Literature. Population Division, Department of Economic and Social Affairs. New York: United Nations. ESA/P/WP.174.

—. 2005. "Population, Development and HIV/AIDS with Particular Emphasis on Poverty. Population Division, Department of Economic and Social Affairs. New York: United Nations (ST/ESA/SER.A/247).

- 2006. Levels and Trends of Contraceptive Use as Assessed in 2002. Population Division, Department of Economic and Social Affairs. New York: United Nations (ST/ESA/SER.A/239).

2007. World Population Prospects: The 2006 Revision, CD-ROM Edition-Extended Dataset in Excel and ASCII formats. Population Division, Department of Economic and Social Affairs. New York: United Nations. E.07.XIII.7. (Special tabulations were prepared for this study.)

Vachot, Laurence et al. 2006. "Sleeping with the enemy: The insidious relationship between dendritic cells and immunodeficiency viruses," in Manfred B. Lutz, Nikolaus Romani, and Alexander Steinkasserer (eds.), Handbook of Dendritic Cells: Biology, Diseases and Therapies. Weinheim: Wiley-VCH, pp. 773-797.

Wawer, Maria J., Ronald H. Gray, Nelson K. Sewankambo et al. 2005. "Rates of HIV-1 transmission per coital act by stage of HIV-1 infection, in Rakai, Uganda," The Journal of Infectious Diseases 191 (1 May): 1403-1409.

Weiss, H. A., M. A. Quigley, and R. J. Hayes. 2000. "Male circumcision and risk of HIV infection in sub-Saharan Africa: A systematic review and meta-analysis,"AIDS 14: 23612370.

Williams, B. G., J. O. Lloyd-Smith, E. Gouws et al. 2006. "The potential impact of male circumcision on HIV in sub-Saharan Africa," PloS Medicine 3(7): e262. DOI: 10.1371/journal.pmed.0030262

WHO. 1999. "Global prevalence and incidence of selected curable sexually transmitted infections," «www.who.int/hiv/pub/sti/who_hiv_aids_2001.02.pdf». 
WHO and UNAIDS. 2006. Progress on global access to HIV antiretroviral therapy. A report on "3 by 5" and beyond. See Annex 1. Estimated number of people receiving antiretroviral therapy, people needing antiretroviral therapy, percentage coverage and numbers of antiretroviral therapy sites in low- and middle-income countries (pp. 71-76). «http:// www.who.int/hiv/fullreport_en_highres.pdf».

—. 2007. "New data on male circumcision and HIV prevention: Policy and programme implications," WHO/UNAIDS Technical Consultation, Male Circumcision and HIV Prevention: Research Implications for Policy and Programming, Montreux, March 2007 «http://data.unaids.org/pub/Report/2007/mc_recommendations_en.pdf». 


\section{APPENDIX: PROJECTING THE DEMOgRAPHIC IMPACT OF THE HIV/AIDS EPIDEMIC}

In the 2006 Revision of the World Population Prospects (United Nations 2007), all countries with HIV prevalence among persons aged 15-49 equal to or greater than 1 percent are considered to be seriously affected by the HIV/AIDS epidemic, and their mortality is projected by modeling explicitly the course of the epidemic and projecting the yearly incidence of HIV infection. Also considered among the affected countries are those where HIV prevalence is lower than 1 percent but whose populations are so large that the number of individuals infected is large, such as Brazil, China, India, and the United States. In total, the course of the epidemic is explicitly modeled for 62 countries.

The model developed by the UNAIDS Reference Group on Estimates, Modelling and Projections (2002), and adopted by the Population Division for its own purposes, was used to fit past estimates of HIV prevalence provided by UNAIDS in 2006 for each of the affected countries. Prevalence levels for countries with large revisions in 2007 were adjusted so as to approximately reflect updates from UNAIDS (2007), and the survival time from infection to death was also slightly increased while refitting the incidence and prevalence trends for all 62 countries. The fitting exercise produces estimates of the model parameters that determine the past dynamics of the epidemic for each country. For most countries, the model parameters are held constant in the past, but beginning in 2005 the parameter reflecting the rate of recruitment of new individuals into the high-risk or susceptible group is projected to decline by half every 20 years, and the parameter representing the force of infection is projected to decline by half every 30 years. These reductions reflect the assumption that changes in behavior among persons subject to the risk of infection, along with increases in access to treatment for those infected, will reduce the chances of transmitting the virus. In addition, the increased survival time of those receiving treatment gradually increases the survival time of all infected persons.

Prevention of mother-to-child transmission is modeled using estimated country-specific coverage rates that average 13 percent in 2005 among the 62 affected countries, but vary from 0 to 90 percent among them. These coverage rates are projected to reach 60 percent on average by 2015, varying between 40 percent and 100 percent among the affected countries (UNAIDS, UNICEF, WHO 2007). After 2015, the coverage rate is assumed to remain constant at the level reached in each of the affected countries until the end of the projection period. Among women receiving treatment, the probability of transmission from mother to child is assumed to be 1 percent. These assumptions produce a reduction in the incidence of HIV infection among children born to HIV-positive women, but the size of the reductions varies from country to country depending on the level of coverage that treatment reaches in each country (Stover et al. 2006).

The survivorship of infected children takes into account varying access to pediatric treatment. HIV-infected children are divided into two groups: (i) for those infected in utero, among whom the disease progresses rapidly, average survival is modeled to be 1.3 years without treatment; and (ii) for those infected after birth through breastfeeding, among whom the disease progresses slowly, average survival is 14 years without treatment (Boerma et al. 2006; Stover et al. 2006). Explicit inclusion of pediatric treatment is achieved via country-specific coverage rates, which average 9 percent in 2005 but vary between 0 and 99 percent among the 62 affected countries. By 2015, the projected coverage is expected to reach 60 percent on average, varying 
from 40 percent to 100 percent among the affected countries (UNAIDS, UNICEF, WHO 2007). Coverage levels remain constant from 2015 to 2050 at the level reached in each country by 2015. The annual survival of children receiving treatment is 95 percent, so that their mean survival time is 19.5 years and the median survival time is 13.5 years in the absence of other causes of death (Stover et al. 2006).

The 2006 Revision incorporates a longer survival for persons receiving treatment with highly active antiretroviral therapy (HAART). The proportion of the HIV-positive population receiving treatment in each country is consistent with estimates prepared by the World Health Organization, which average 25 percent in 2005 but vary between 0 and 100 percent among the 62 affected countries (WHO and UNAIDS 2006) Coverage is projected to reach between 40 percent and 100 percent by 2015, averaging 60 percent for the affected countries. Between 2015 and 2050, coverage levels remain constant at the level reached in each country by 2015 . It is assumed that adults receiving treatment have, on average, a 90 percent chance of surviving each year in the absence of other causes of death. Under this assumption, mean survival time after the initiation of therapy is 9.5 years and the median survival time is 6.6 years in the absence of other causes of death. Therapy is assumed to start at the time full-blown AIDS develops. Without treatment, infected adults have a mean survival time of two years after the onset of full-blown AIDS.

The above procedures apply to the 62 AIDS countries included in the 2006 Revision. For the present study the following additional assumptions were made to obtain comprehensive regional estimates of various indicators.

1) According to estimates of the number of infected individuals for all countries in the world prepared by UNAIDS (2006), the 62 AIDS countries in the 2006 Revision cover 92.8 percent of infected adults in the world. To adjust for this difference, all other "non-AIDS" countries have been given an HIV prevalence rate of 0.17 percent and an incidence rate 0.018 percent in 2005. In each region the time pattern of prevalence and incidence in the non-AIDS countries is assumed to be the same as in the AIDS countries, except for Europe where the non-AIDS countries are in Western Europe and the AIDS countries are in Eastern Europe. The Western European time pattern is assumed to be the same as in the United States (except at a lower level).

2) According to estimates of AIDS deaths for all countries in the world prepared by UNAIDS (2006), the 62 AIDS countries in the 2006 Revision cover 96 percent of AIDS deaths in the world. AIDS deaths in every region have been inflated by a factor 1/0.96 to obtain regional totals. 
Figure 1. HIV prevalence rate among adults aged $15-49$, by region, 2005

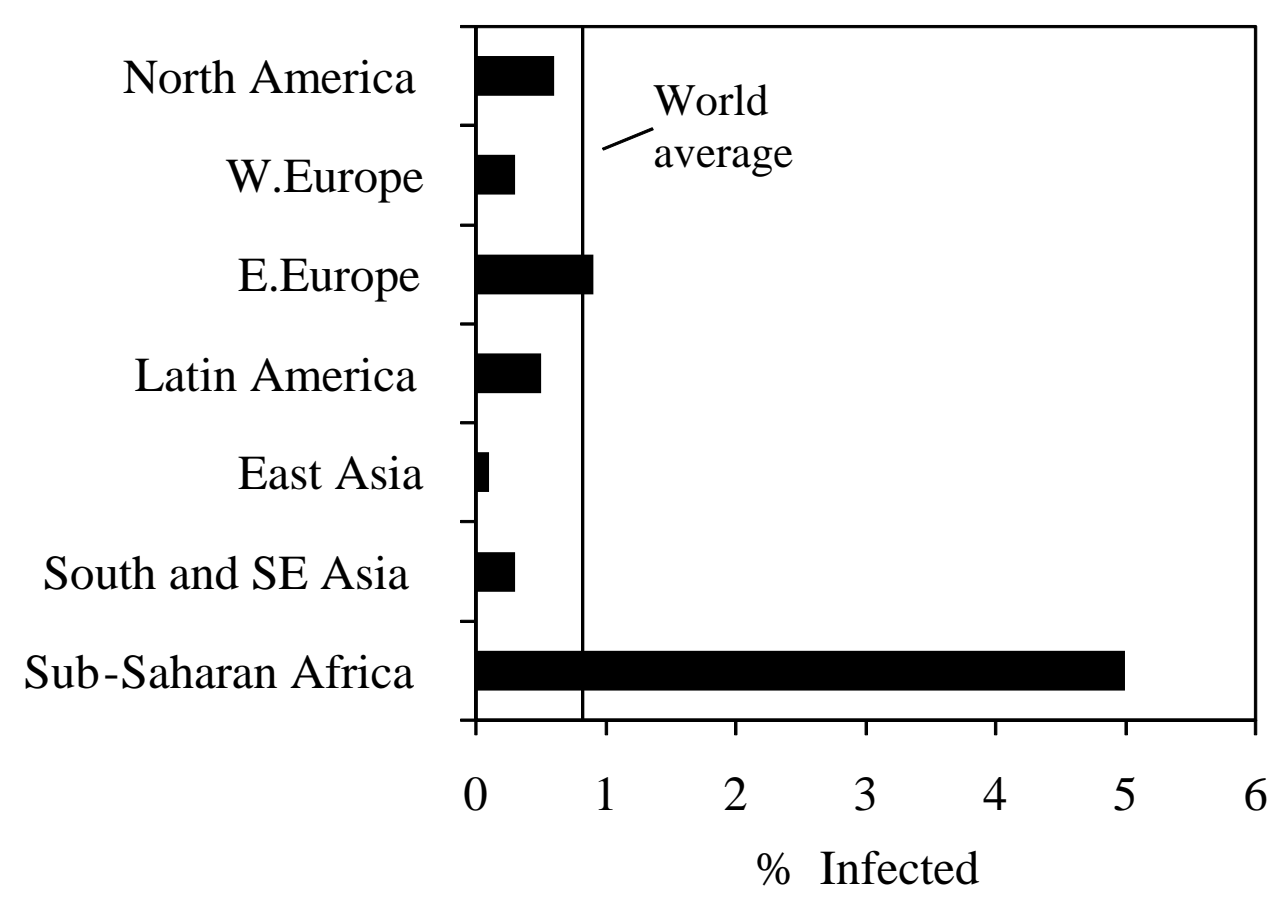

Source: UNAIDS 2007.

Figure 2. Geographic distribution of the HIV epidemic

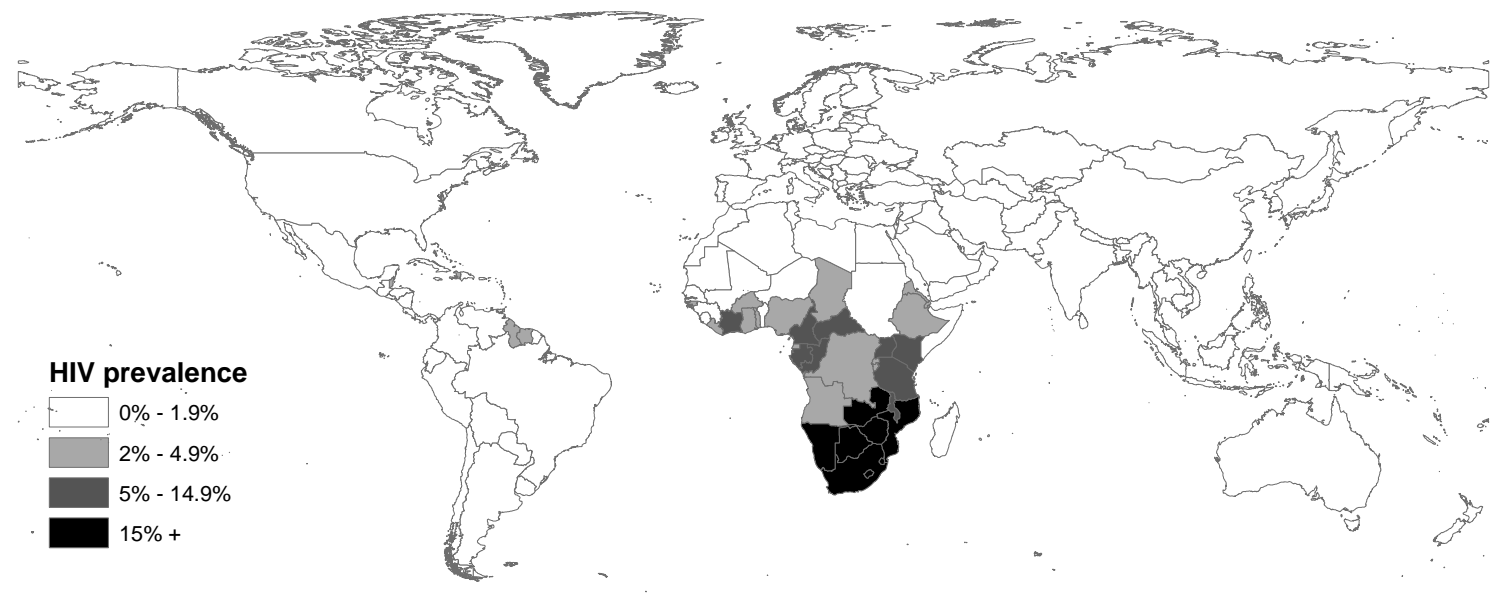

Source: United Nations 2007. 
Figure 3. HIV prevalence rate among adults aged $15-49$ by region, estimates and projections

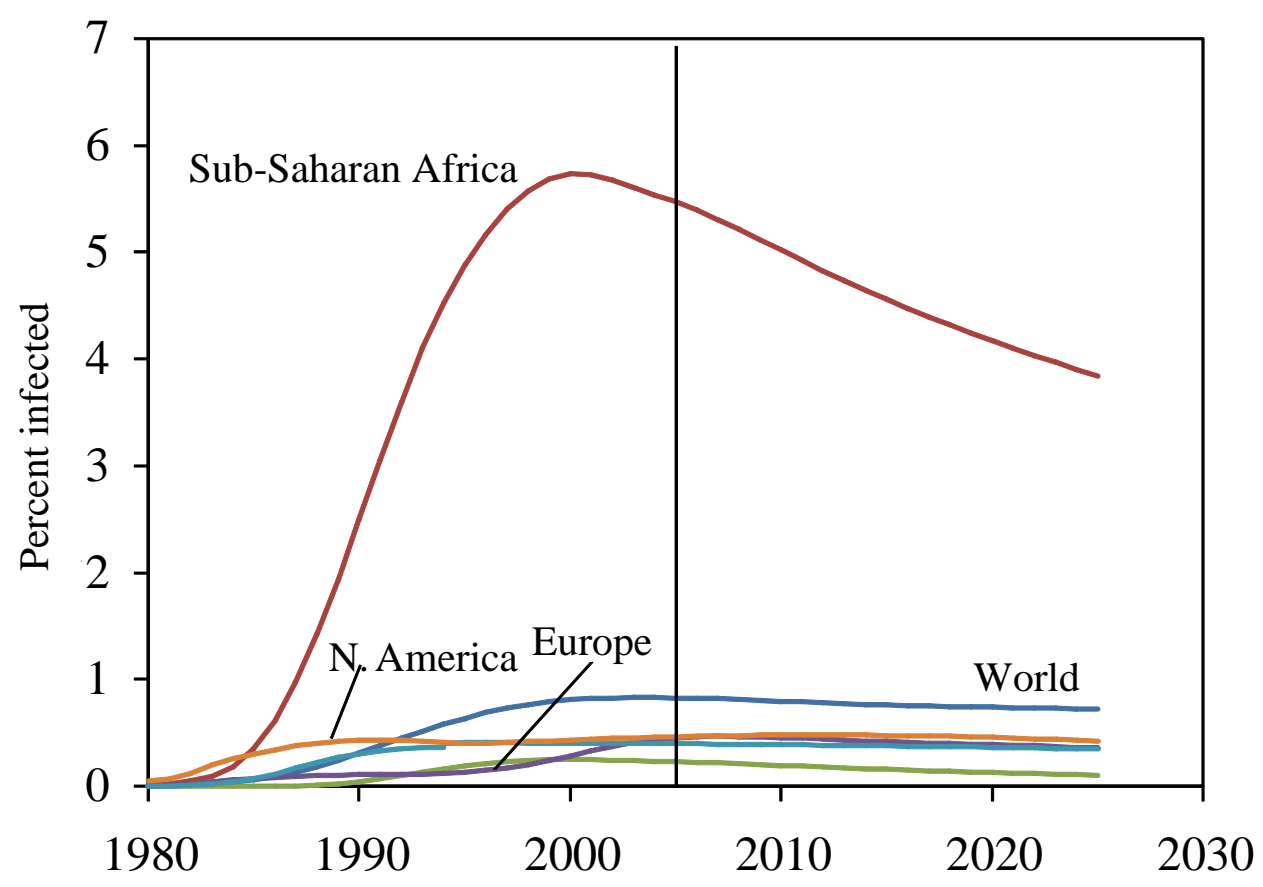

Source: United Nations 2007.

Figure 4. HIV prevalence rate among adults aged 15-49 in 40 countries in sub-Saharan Africa, estimates and projections

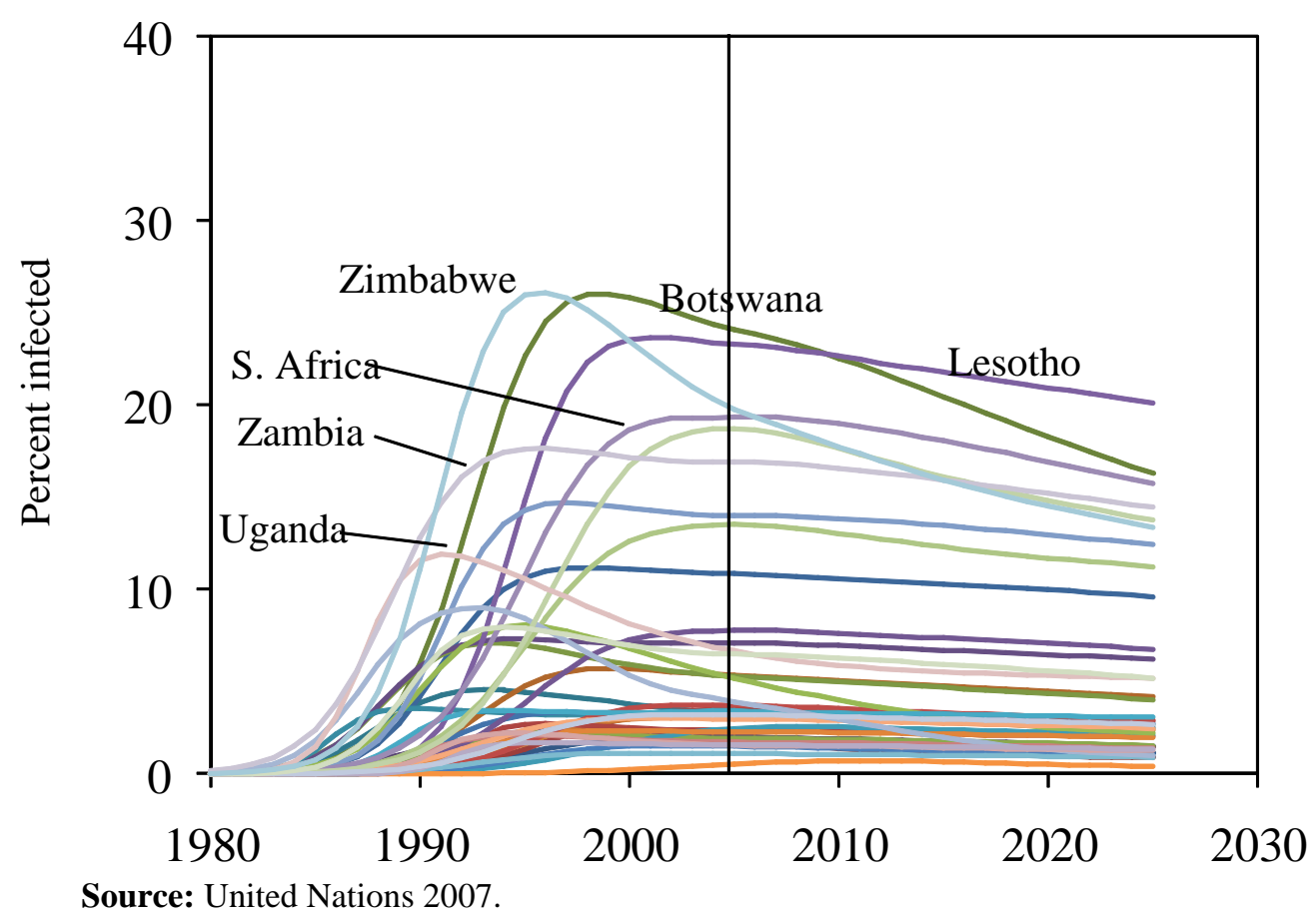


Figure 5. HIV incidence rates among adults aged 15-49 by region, estimates and projections

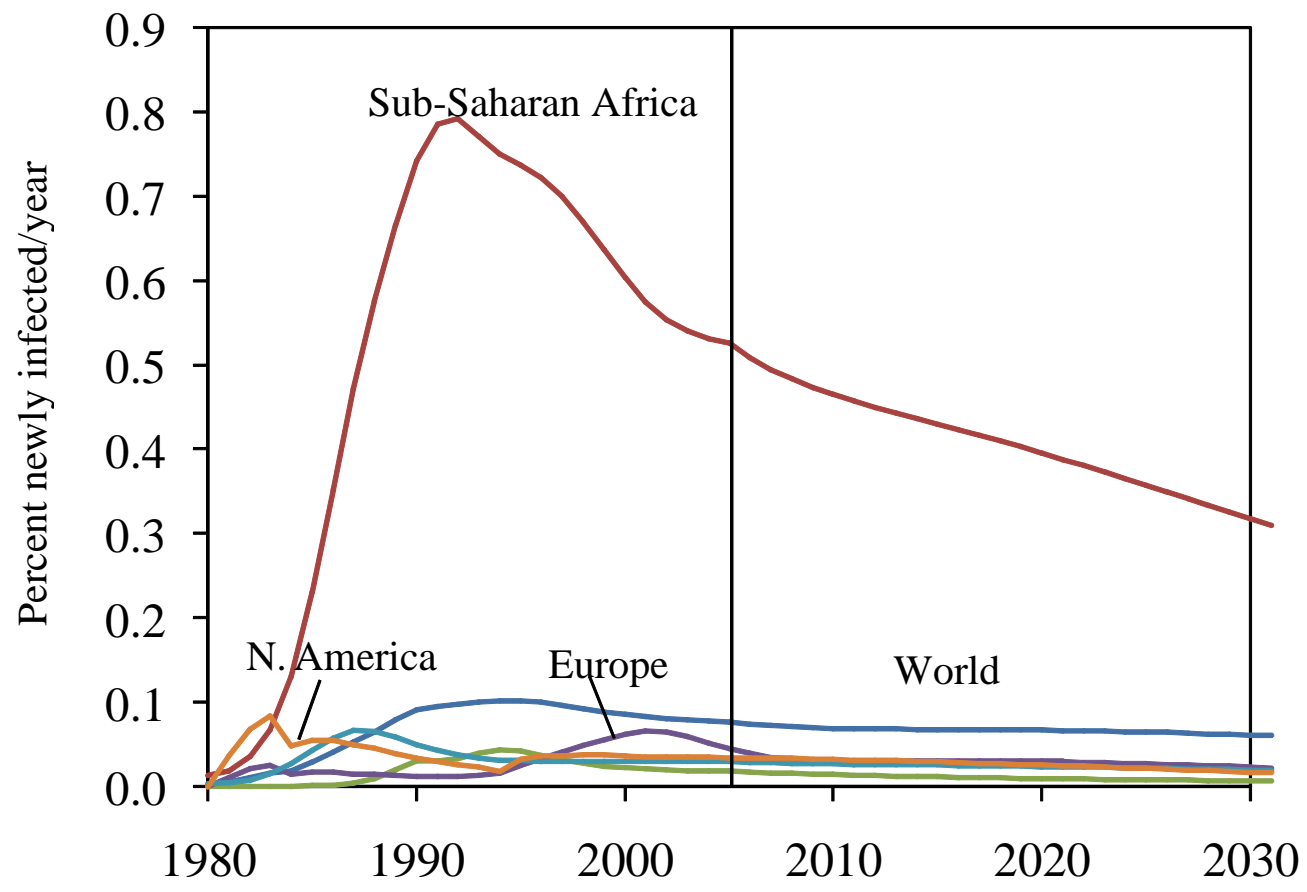

Source: United Nations 2007.

Figure 6. Peak years of past incidence and prevalence rates among adults aged $15-49$ by region

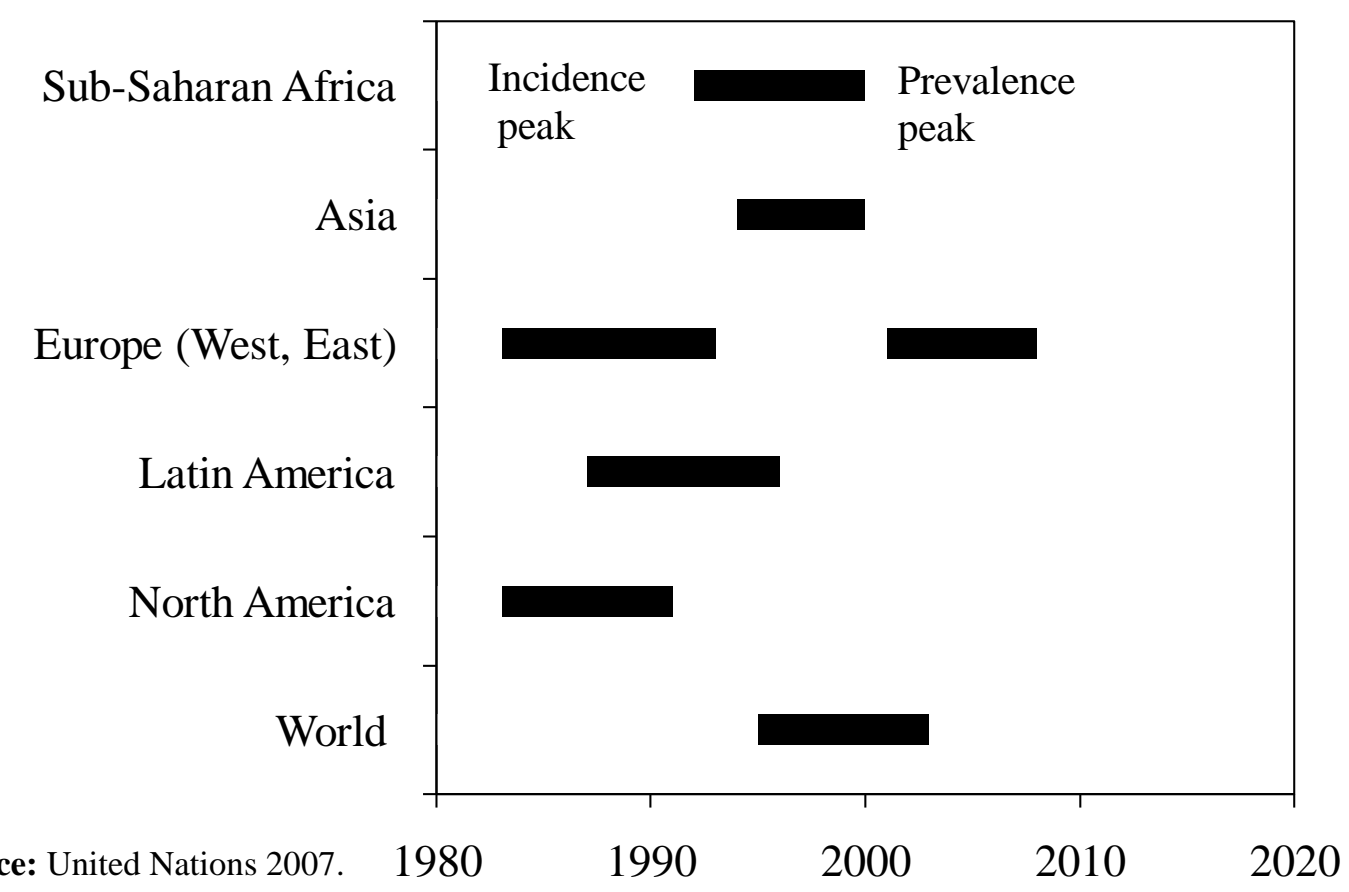


Figure 7. Annual number of new HIV infections among adults aged $15-49$ by region, estimates and projections

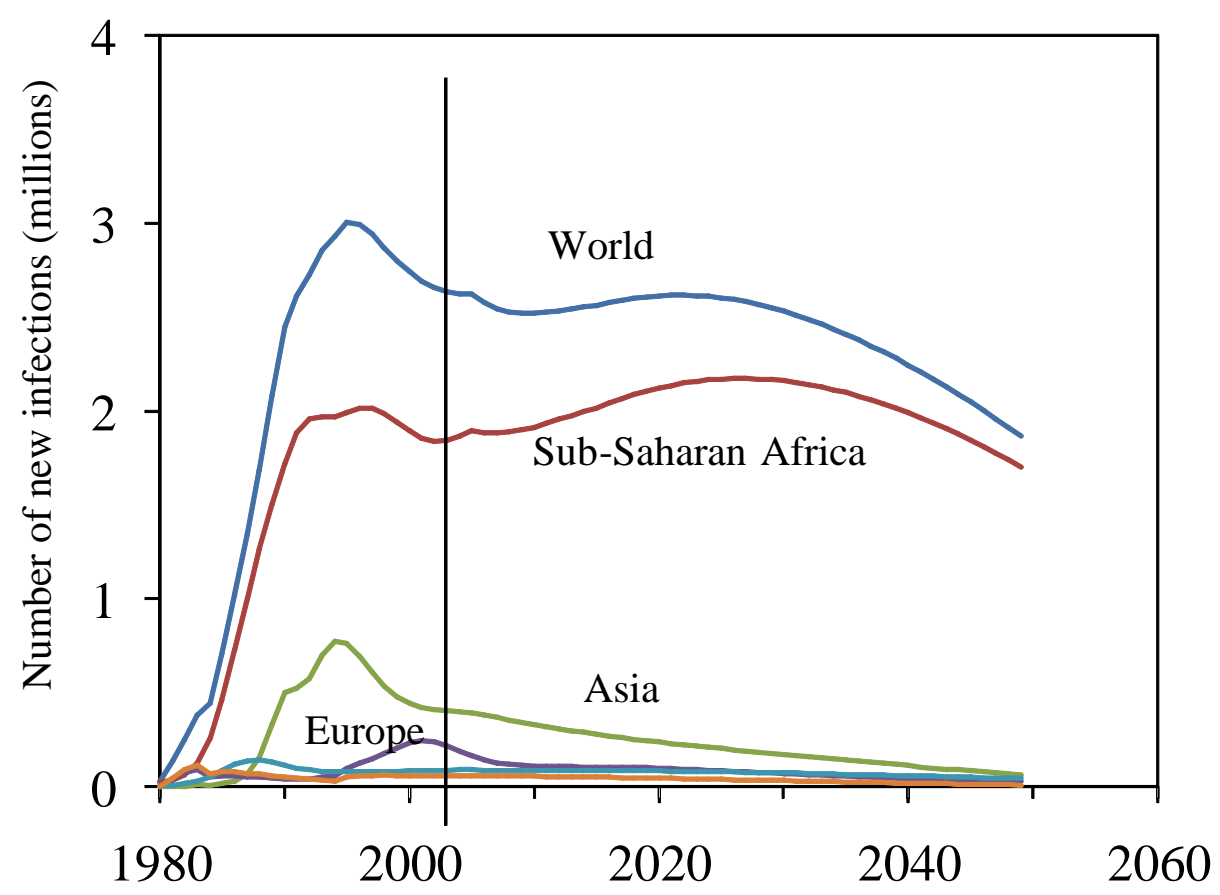

Source:: United Nations 2007.

Figure 8. Number of HIV-infected adults aged 15-49 by region, estimates and projections

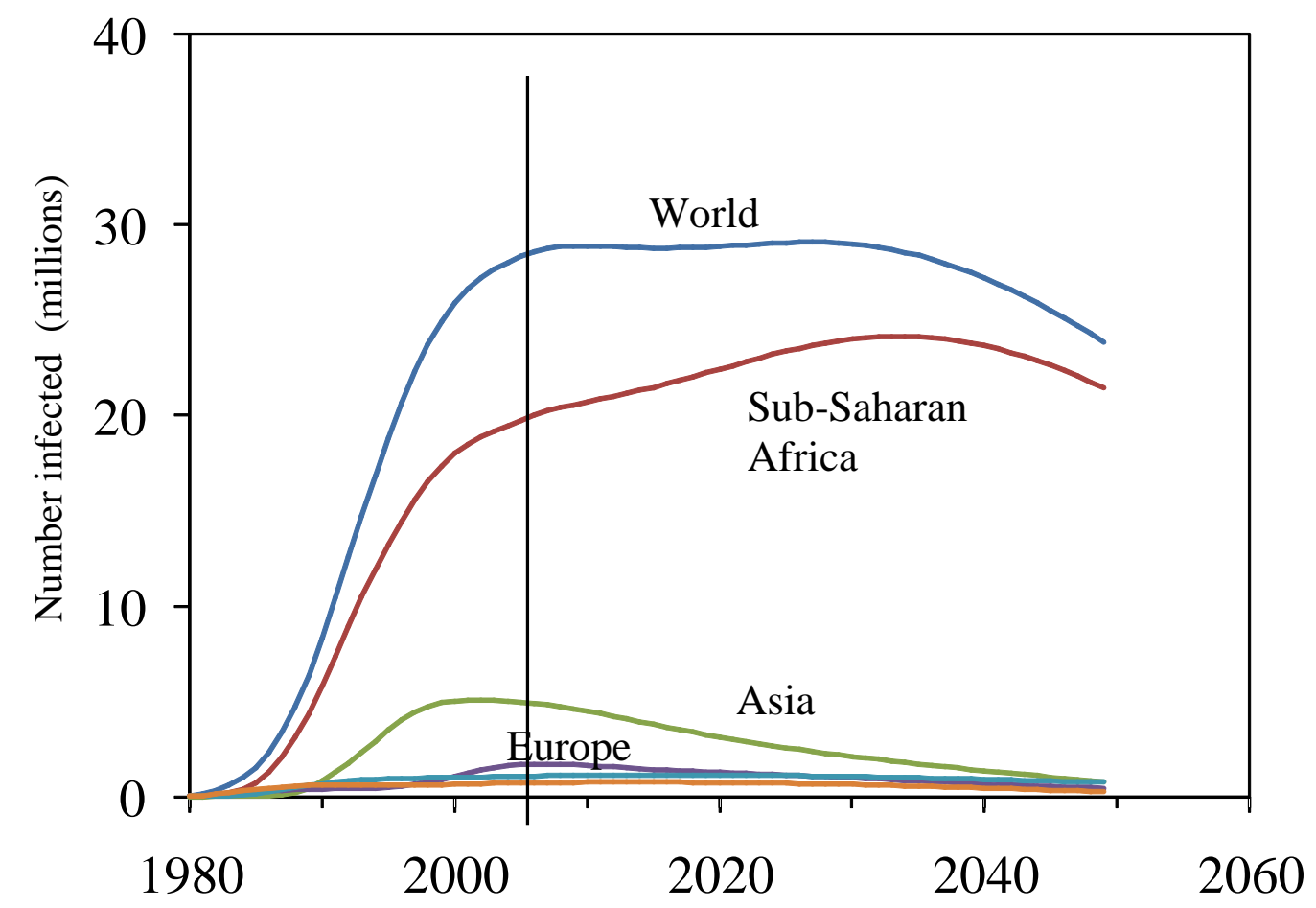

Source: United Nations 2007. 
Figure 9. HIV prevalence rate among adults aged 15-49 in sub-Saharan Africa, reference projection (no additional prevention technology) and projection with no new infections after 2010

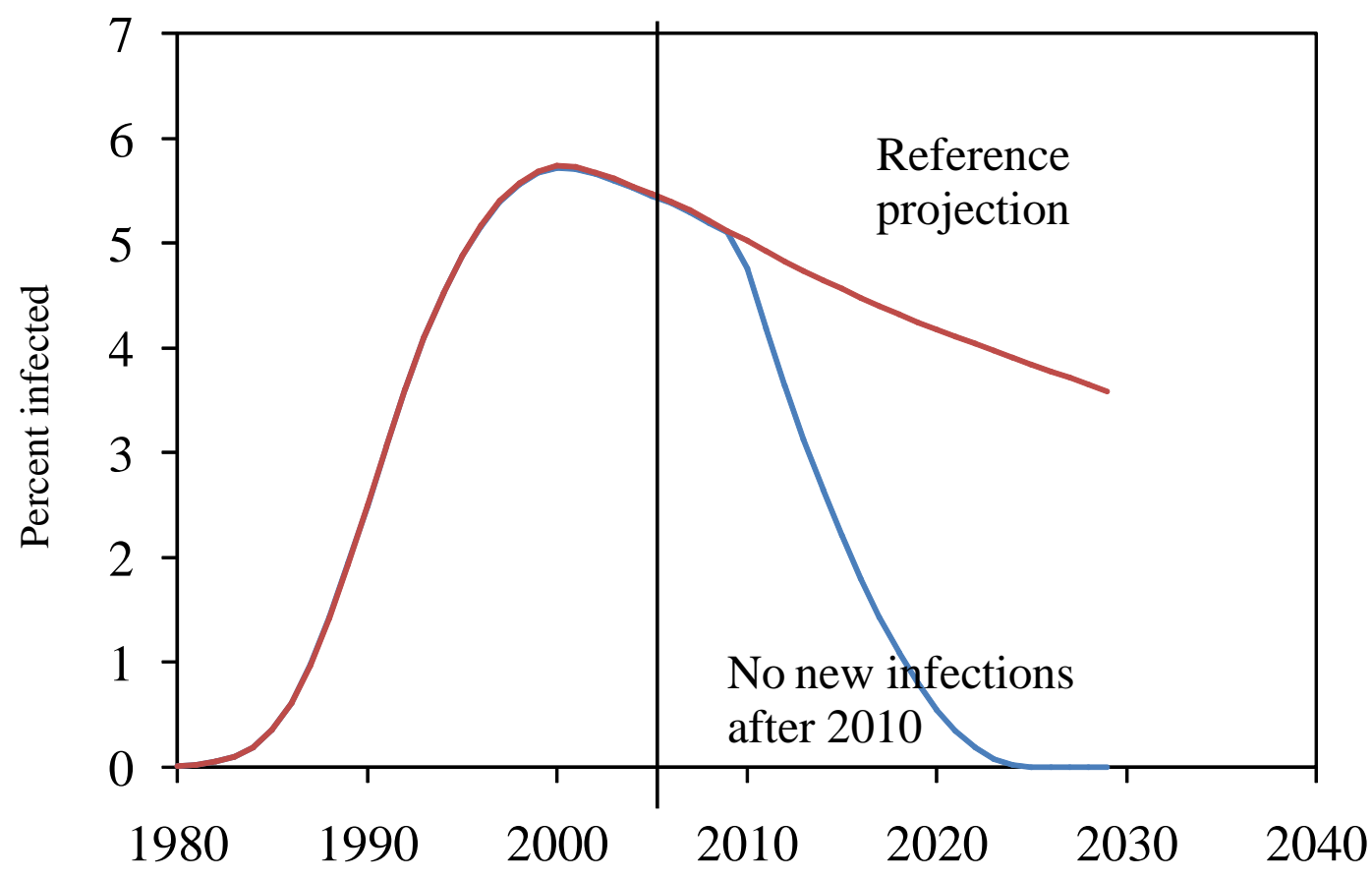

Source: United Nations 2007. 
Figure 10A. Crude death rate with and without AIDS in sub-Saharan Africa, 1980-2050

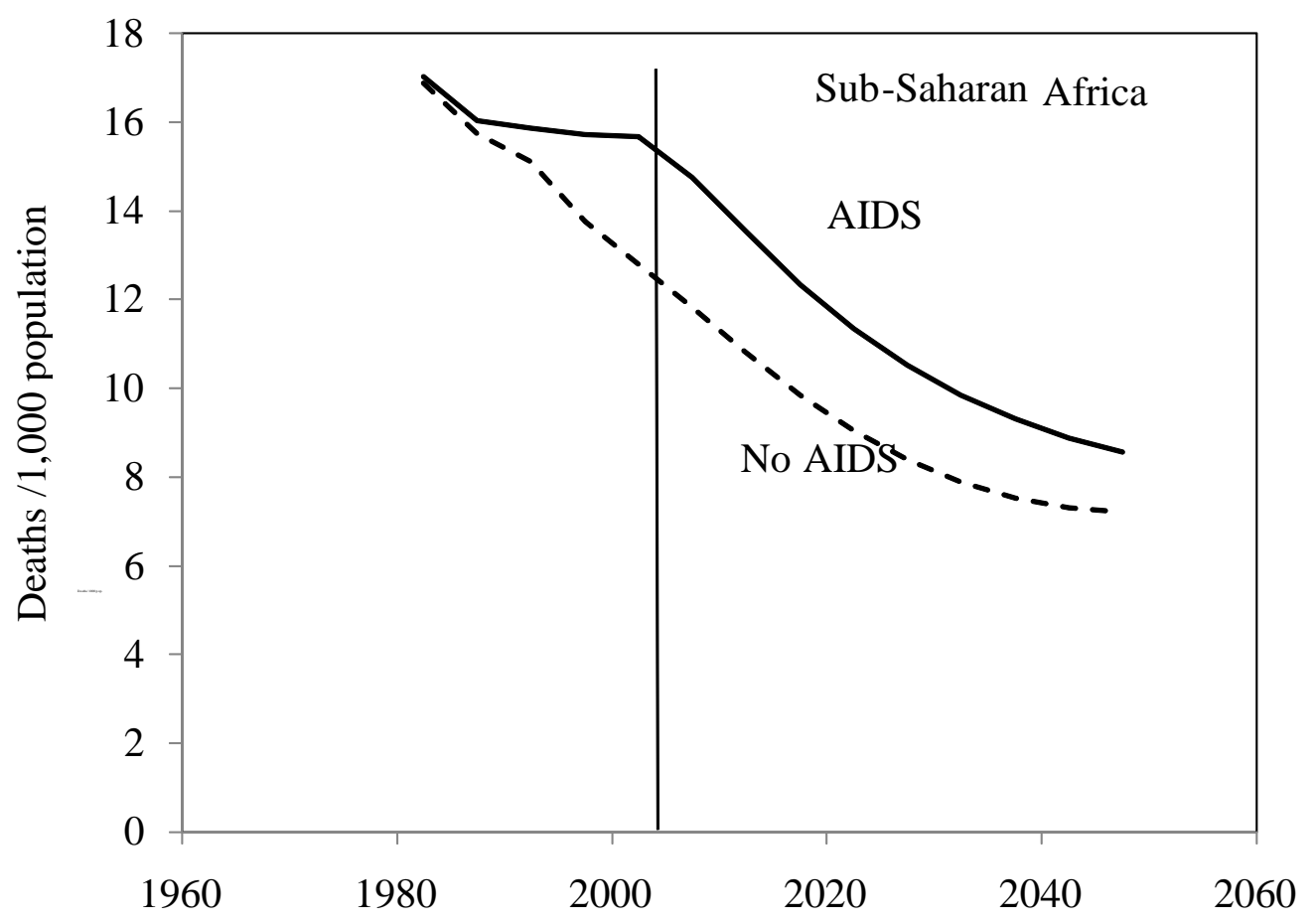

Figure 10B. Crude death rate with and without AIDS in Europe, North America, Asia, and Latin America, 1980-2050

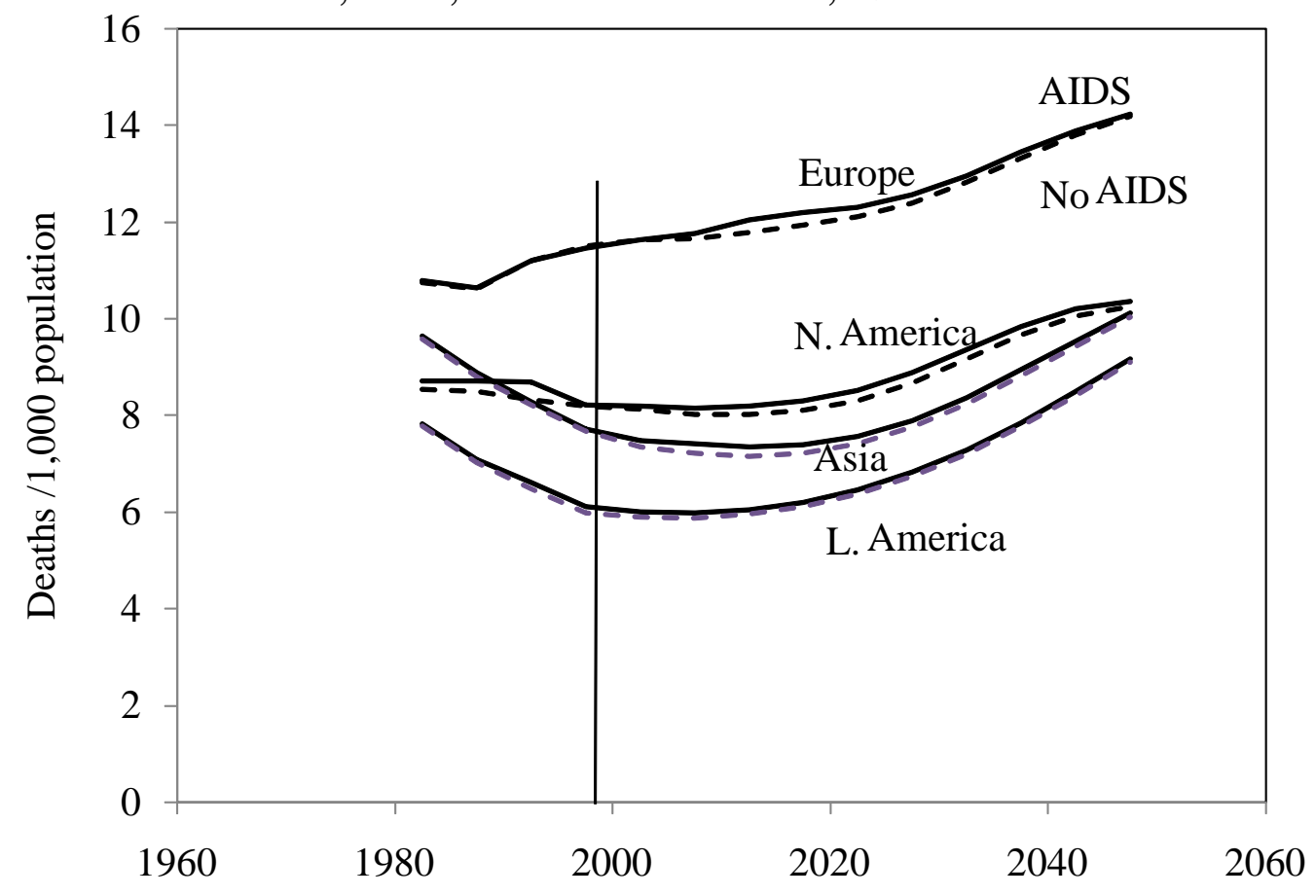


Figure 11. Population by sex and age group, with and without AIDS, sub-Saharan Africa, 2015

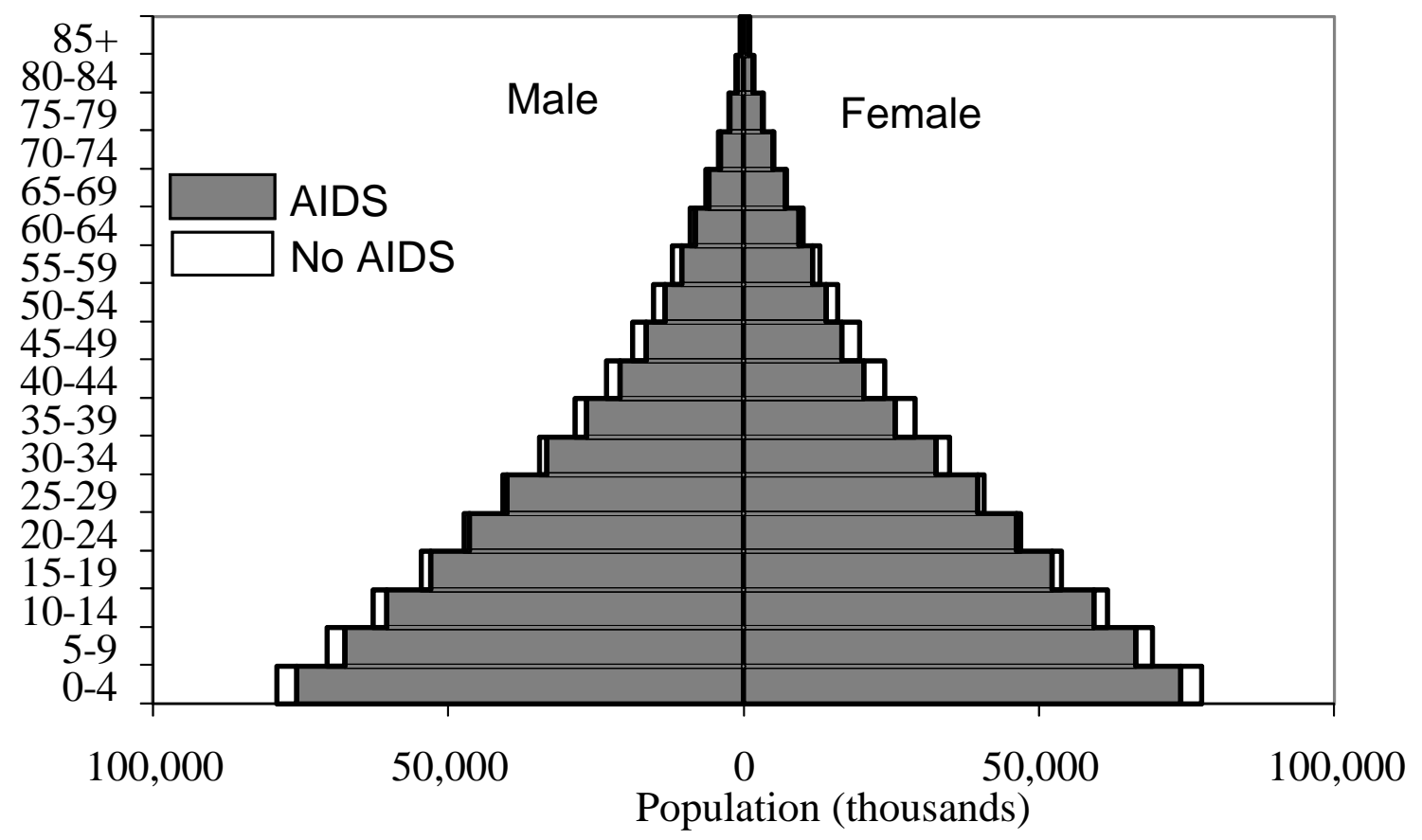

Figure 12. Population by sex and age group, with and without AIDS, South Africa, 2015

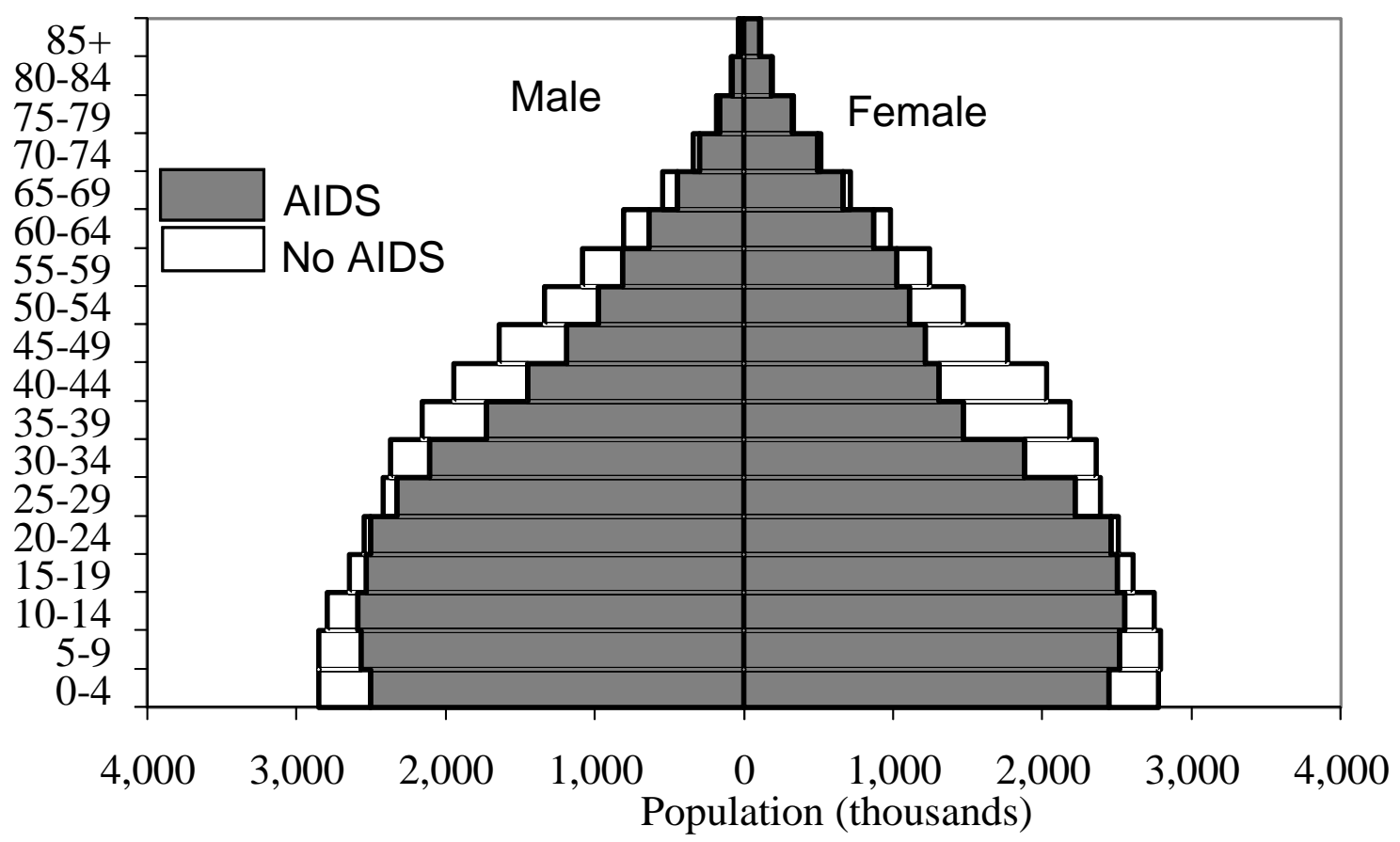


Figure 13. Percent change in population size between 2005 and 2050 with and without AIDS, by region

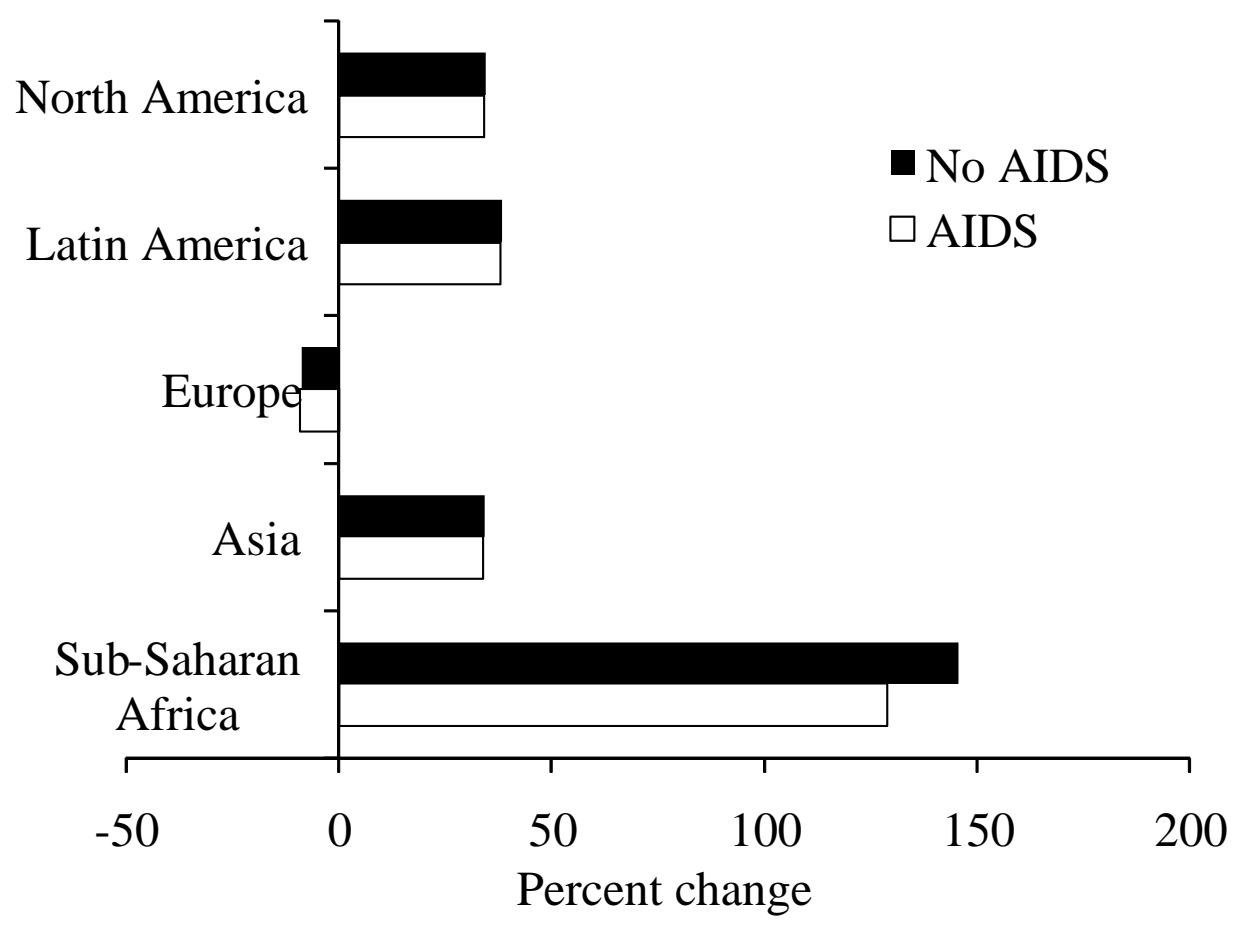

Figure 14. Population size of sub-Saharan Africa with and without AIDS, estimates and projections

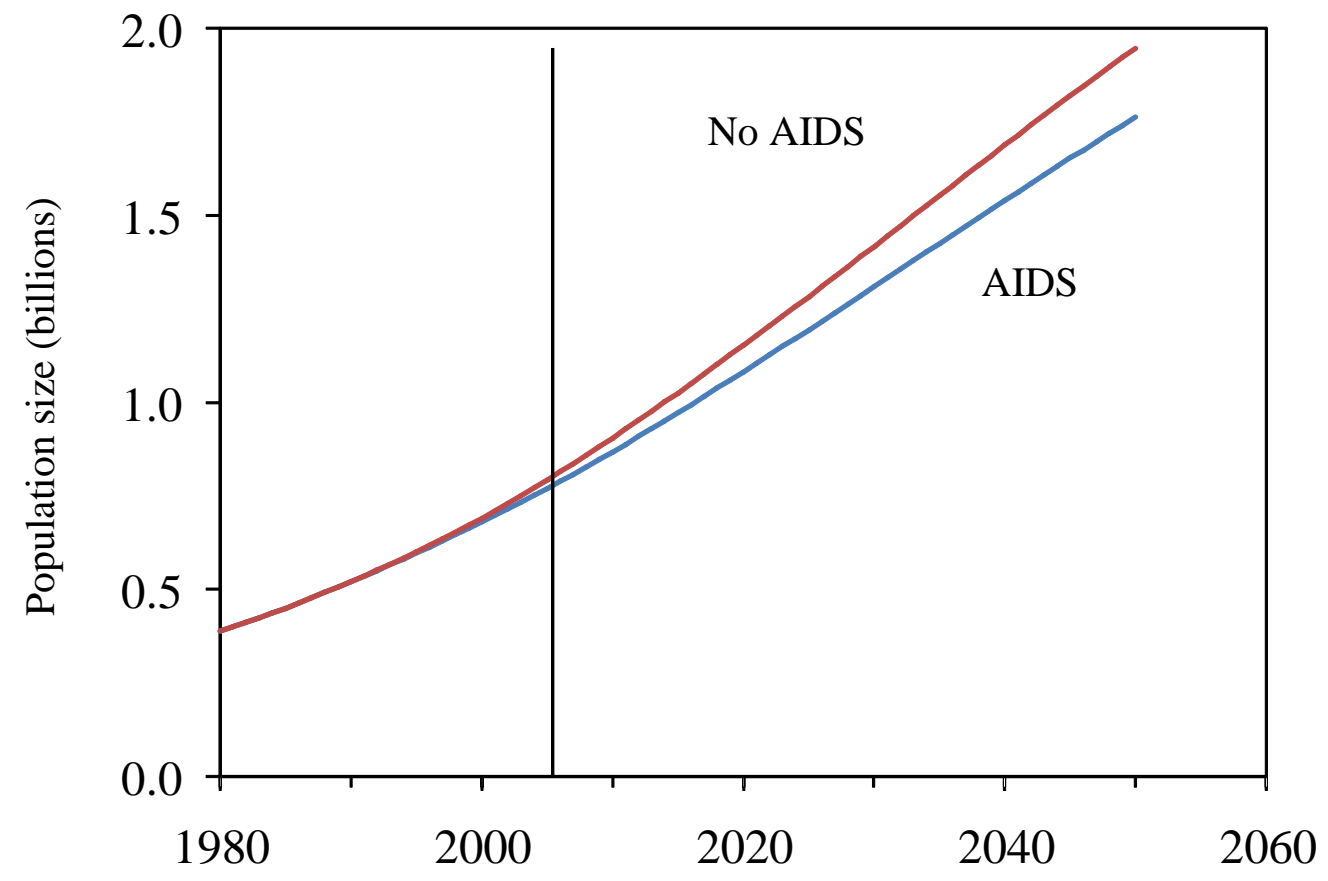




\section{Poverty, Gender, and Youth Working Papers}

If still in print, single copies of up to three working papers from 1989 through 2003 are available free of charge.

Beginning with the 2004 issues, working papers are no longer available in print format. Instead they are distributed electronically. As each new paper is completed, subscribers are notified by e-mail and a link to the paper is provided.

To subscribe to the Poverty, Gender, and Youth working paper e-mail notification list, or to obtain back issues from 1989 to 2003, please send your request to pgywp@ popcouncil.org.

PDFs of recent issues are available at www.popcouncil.org/publications/wp/index.html

2008

9 John Bongaarts, Thomas Buettner, Gerhard Heilig, and François Pelletier, "Has the HIV epidemic peaked?"

8 Barbara S. Mensch, Paul C. Hewett, Richard Gregory, and Stephane Helleringer, "Sexual behavior and STI/HIV status among adolescents in rural Malawi: An evaluation of the effect of interview mode on reporting."

7 John Bongaarts, "Fertility transitions in developing countries: Progress or stagnation?"

2007

6 Cynthia B. Lloyd, "The role of schools in promoting sexual and reproductive health among adolescents in developing countries."

5 Ann Biddlecom, Richard Gregory, Cynthia B. Lloyd, and Barbara S. Mensch, "Premarital sex and schooling transitions in four subSaharan African countries."

4 Sajeda Amin, John B. Casterline, and Laura Spess, "Poverty and fertility: Evidence and agenda."
3 Bussarawan Teerawichitchainan and James F. Phillips, "Ethnic differentials in parental health seeking for childhood illness in Vietnam."

2 Zachary Zimmer, Kim Korinek, John Knodel, and Napaporn Chayovan, "Support by migrants to their elderly parents in rural Cambodia and Thailand: A comparative study."

1 Sharon Ghuman and Cynthia B. Lloyd, "Teacher absence as a factor in gender inequalities in access to primary schooling in rural Pakistan."

\section{Policy Research Division working papers}

2006

219 Cynthia B. Lloyd and Barbara S. Mensch, "Marriage and childbirth as factors in school exit: An analysis of DHS data from sub-Saharan Africa."

218 Ayaga A. Bawah, James F. Phillips, Martin Adjuik, Maya VaughanSmith, Bruce MacLeod, and Fred N. Binka, "The impact of immunization on the association between poverty and child survival: Evidence from Kassena-Nankana District of northern Ghana." 
217 Zachary Zimmer, "Poverty, wealth inequality, and health among older adults in rural Cambodia."

216 John Bongaarts, "Late marriage and the HIV epidemic in sub-Saharan Africa."

215 John Bongaarts, "How long will we live?"

214 Zachary Zimmer, Toshiko Kaneda, and Laura Spess, "Urban versus rural mortality among older adults in China."

213 Paul Demeny and Geoffrey McNicoll, "The political demography of the world system, 2000-2050."

212 Monica Grant and Kelly Hallman, "Pregnancy-related school dropout and prior school performance in South Africa."

211 Kelly Hallman, Sara Peracca, Jennifer Catino, and Marta Julia Ruiz, "Multiple disadvantages of Mayan females: The effect of gender, ethnicity, poverty, and residence on education in Guatemala."

210 Geoffrey McNicoll, "Policy lessons of the East Asian demographic transition."

209 Cynthia B. Lloyd, Cem Mete, and Monica J. Grant, "The implications of changing educational and family circumstances for children's grade progression in rural Pakistan: 19972004." 